Portland State University

PDXScholar

\title{
Tidal-Fluvial and Estuarine Processes in the Lower Columbia River: II. Water Level Models, Floodplain Wetland Inundation, and System Zones
}

\author{
David A. Jay \\ Portland State University, djay@pdx.edu \\ Amy B. Borde \\ Pacific Northwest National Laboratory \\ Heida Diefenderfer \\ Pacific Northwest National Laboratory
}

Follow this and additional works at: https://pdxscholar.library.pdx.edu/cengin_fac

Part of the Civil and Environmental Engineering Commons, Fresh Water Studies Commons, and the Hydrology Commons

Let us know how access to this document benefits you.

\section{Citation Details}

Jay, D. A., Borde, A. B., \& Diefenderfer, H. L. (2016). Tidal-Fluvial and Estuarine Processes in the Lower Columbia River: II. Water Level Models, Floodplain Wetland Inundation, and System Zones. Estuaries and Coasts, 39(5), 1299-1324. http://doi.org/10.1007/s12237-016-0082-4

This Article is brought to you for free and open access. It has been accepted for inclusion in Civil and Environmental Engineering Faculty Publications and Presentations by an authorized administrator of PDXScholar. Please contact us if we can make this document more accessible: pdxscholar@pdx.edu. 


\title{
Tidal-Fluvial and Estuarine Processes in the Lower Columbia River: II. Water Level Models, Floodplain Wetland Inundation, and System Zones
}

\author{
David A. Jay ${ }^{1}$ • Amy B. Borde ${ }^{2}$ Heida L. Diefenderfer ${ }^{2}$
}

Received: 29 July 2015 /Revised: 29 December 2015 / Accepted: 18 February 2016/Published online: 26 April 2016

(C) Coastal and Estuarine Research Federation 2016

\begin{abstract}
Spatially varying water-level regimes are a factor controlling estuarine and tidal-fluvial wetland vegetation patterns. As described in Part I, water levels in the Lower Columbia River and estuary (LCRE) are influenced by tides, river flow, hydropower operations, and coastal processes. In Part II, regression models based on tidal theory are used to quantify the role of these processes in determining water levels in the mainstem river and floodplain wetlands, and to provide 21-year inundation hindcasts. Analyses are conducted at 19 LCRE mainstem channel stations and 23 tidally exposed floodplain wetland stations. Sum exceedance values (SEVs) are used to compare wetland hydrologic regimes at different locations on the river floodplain. A new predictive tool is introduced and validated, the potential SEV (pSEV), which can reduce the need for extensive new data collection in wetland restoration planning. Models of water levels and inundation frequency distinguish four zones encompassing eight reaches. The system zones
\end{abstract}

Communicated by David K. Ralston

Electronic supplementary material The online version of this article (doi:10.1007/s12237-016-0082-4) contains supplementary material, which is available to authorized users.

David A. Jay

djay@cecs.pdx.edu

Amy B. Borde

amy.borde@pnnl.gov

Heida L. Diefenderfer

heida.diefenderfer@pnnl.gov

1 Department of Civil and Environmental Engineering, Portland State University, P.O. Box 751, Portland, OR 97207-0751, USA

2 Pacific Northwest National Laboratory, Marine Sciences Laboratory, 1529 West Sequim Bay Road, Sequim, WA 98382, USA are the wave- and current-dominated Entrance to river kilometer (rkm) 5; the Estuary (rkm-5 to 87), comprised of a lower reach with salinity, the energy minimum (where the turbidity maximum normally occurs), and an upper estuary reach without salinity; the Tidal River (rkm-87 to 229), with lower, middle, and upper reaches in which river flow becomes increasingly dominant over tides in determining water levels; and the steep and weakly tidal Cascade (rkm-229 to 234) immediately downstream from Bonneville Dam. The same zonation is seen in the water levels of floodplain stations, with considerable modification of tidal properties. The system zones and reaches defined here reflect geological features and their boundaries are congruent with five wetland vegetation zones.

Keywords Environmental flows · Estuarine processes · Hydropower impacts $\cdot$ Non-stationary tides $\cdot$ Sum exceedance value $\cdot$ Tidal freshwater $\cdot$ Tidal river zonation $\cdot$ Tides . Wetlands · Water levels

\section{Introduction}

Systematic integration of physical and biological concepts and analyses is essential to understanding, conserving, and restoring fluvial and estuarine ecosystems (Geyer et al. 2000; Rieman et al. 2006). In river floodplains, for example, the variability of hydrologic regimes is fundamental to distribution of the biota (Poff et al. 1997; Junk 1999; Bunn and Arthington 2002). Inundation dynamics affect the gradient of wetland plant species composition from tidal freshwater and oligohaline marshes (Hudon 1997; Baldwin et al. 2001; Sharpe and Baldwin 2013) to brackish and salt marshes (Cornu and Sadro 2002; Moffett et al. 2010). Anthropogenic modifications further complicate natural disturbance regimes and affect ecosystem resilience (Picket and White 1985; Kingsford 2000). Quantifying the 
hydrologic and other factors affecting zonation and productivity in these ecosystems remains a challenge, because salinity, competition, root-zone aeration, and drying are subject to geographic variability at multiple scales from the latitudinal to local within a single river (Ewing 1986; Pennings et al. 2005).

The $234 \mathrm{~km}$ lower Columbia River and estuary (LCRE) region (Fig. 1), one of the largest complexes of tidal wetlands on the West Coast of North America (Callaway et al. 2012), encompasses a mosaic of channel, peripheral floodplain, and wetland habitats, many vegetated (Christy and Putera 1993). However, high percentages of all wetland types have been lost to diking and filling, or degraded by practices including water withdrawals, upslope logging, and grazing (Thomas 1984; Christy and Putera 1993; Kukulka and Jay 2003b). Wetland restoration is underway in the LCRE, in part because of its potential to increase populations of threatened and endangered salmon by increasing survival of out-migrating juveniles through direct habitat and indirect food web functions (Peterson 2003; NMFS 2008; Diefenderfer et al. 2011). Understanding and restoring the vegetation patterns and the tidal wetland ecosystems requires definition of the underlying water-level regime. As discussed in Part I (Jay et al. 2014, hereafter referred to as Part I), there is a continuum in waterlevel patterns from the tide- and wave-dominated zone near the ocean to the fluvially dominated, more landward part of the system. This diversity arises primarily because of the change in the relative importance of tidal and coastal vs. fluvial processes, but also because of the considerable modification of the tide as it propagates landward, and factors such as topographic confinement of the channel.

The LCRE study area (Fig. 1) and previous analyses of the system were described in Part I. Marsh, shrub, and forestedwetland communities are arrayed on elevational gradients in the lower river (Thomas 1984; Fox et al. 1984). However, the hydrologic regimes associated with these communities have not been quantified sufficiently along either lateral or longitudinal gradients for predictive models of restoration effects to be developed, particularly in the $200 \mathrm{~km}$ LCRE tidal freshwater region. A recent river reach classification system for the LCRE places considerable weight on the location of tributary mouths, Environmental Protection Agency ecoregions, and physiographic features (Simenstad et al. 2011). LCRE restoration plans must, however, also consider the fluid-mechanical process gradient from wave-dominated to tidal, tidal-fluvial, and fluvially dominated hydrologic zones (cf., Part I; Sherwood et al. 1990; Jay et al. 1990; Chawla et al. 2008). Like other large river floodplains, both lateral and longitudinal gradients in hydrologic regimes and biota are evident (Fox et al. 1984; Bunn and Arthington 2002). Yet the quantification of these gradients needed to support ecological restoration designs (Poff et al. 1997) has only been partially accomplished, with emphasis on the lower estuary, where the extent of saltwater intrusion as governed by seasonal flows is usually about 20 to $40 \mathrm{~km}$ (Jay and Smith 1990).

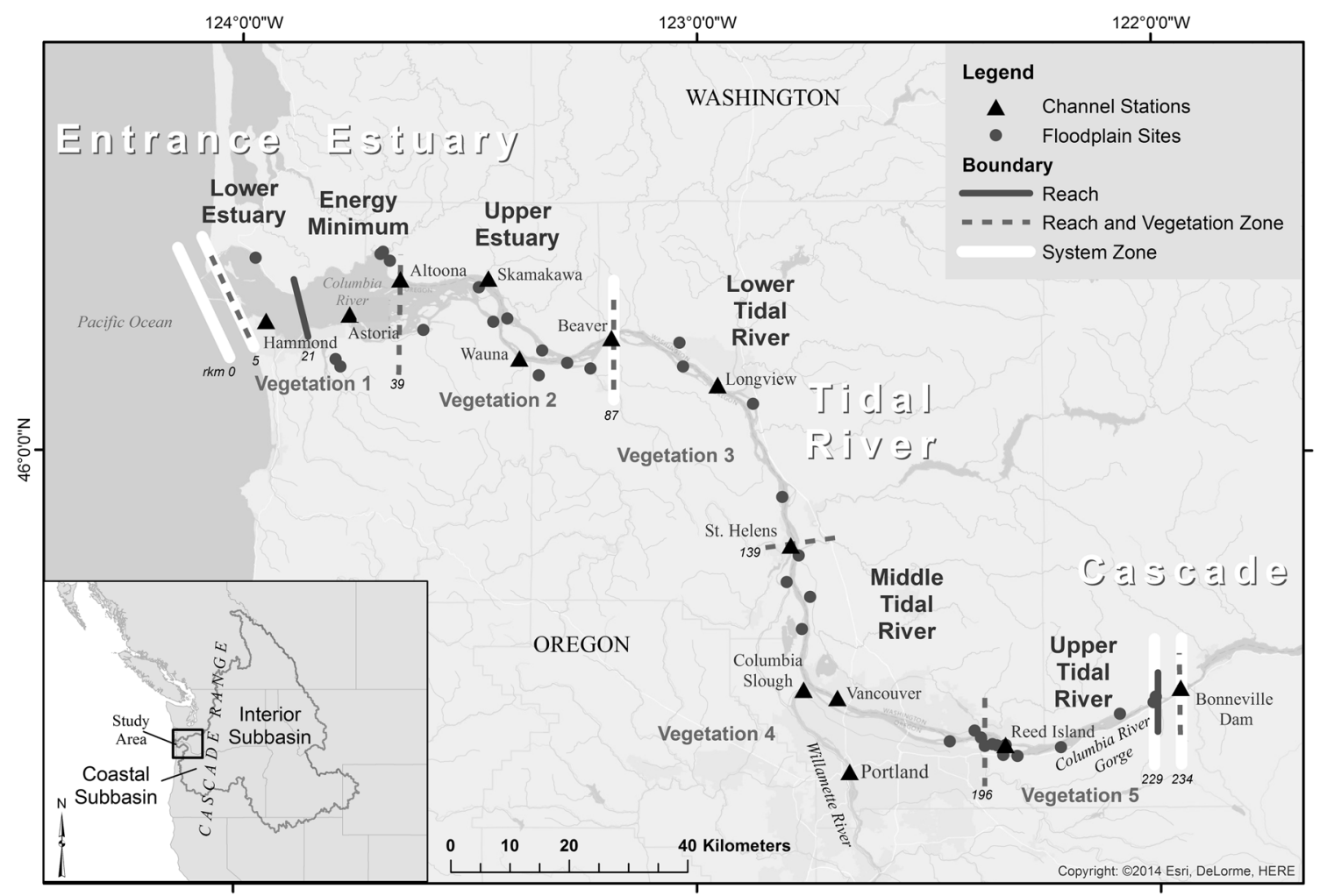

Fig. 1 Lower Columbia River and estuary (LCRE) place names and system zonation 
Borde et al. (2012a, b) analyzed plant community, environmental, and water-level data from 54 tidal wetlands throughout the LCRE and defined five potential herbaceous tidal wetland vegetation zones (Fig. 1). Here, we use the term potential vegetation in the sense of Kuchler (1964), to represent the flora that a geographical area has the capacity to support, given its characteristic climatic and hydrological regime. However, our zones do reflect the current, managed hydrograph (not undisturbed conditions) because they were defined from wetland plant data collected at marshes along the mainstem river during the past decade. While the existence of the zones is clear, there is some uncertainty in the location of the boundaries between the zones, due to the limited availability of wetland sampling sites. The most seaward zone (the Lower Estuary) extends from the ocean entrance to an upper boundary at about rkm-39. The second zone, the Upper Estuary, is characterized by a mix of tidal and fluvially driven inundation; its landward boundary is between $\mathrm{rkm}-87$ and rkm-104. Wetlands in this zone (and all zones more landward) have the vegetative characteristics of tidal freshwater wetlands, despite the variations in their physical and geomorphic settings. The third zone is the Lower Tidal River, where an increased degree of wetland inundation occurs during the growing season; currently available data indicate that it has an upper boundary near rkm-139. The fourth vegetation zone is the Middle Tidal River, including the floodplain around the mouth of the Willamette River. It has even more depth and duration of inundation during the growing season and extends to about rkm-196, the entrance to the Columbia River Gorge. The final vegetation zone is the Upper Tidal River, with very high inundation during the growing season and very low inundation during the rest of the year. The species assemblages characteristic of the LCRE are described elsewhere (Christy and Putera 1993; Kunze 1994; Callaway et al. 2012; Borde et al. 2012a, b). The zones do not represent the distribution of trees and shrubs, e.g., the upper extent of the dominant coastal tree, Sitka spruce (Picea sitchensis), is $\sim \mathrm{rkm}-64$.

Here, regression models based on tidal theory are used to quantify the influence of tidal range, river flow, coastal forcing and hydropower operations (power-peaking) on water levels at 18 channel stations. Specifically, we model lower-low water (LLW), mean water level (MWL) and higher-high water (HHW) throughout the system as a function of external forcing and construct 21-year histories of each of these datums to describe inundation. We conduct similar analyses for 23 floodplain wetland stations using the longer channel records to guide wetland model formation. Finally, we use tidal wetland data from Borde et al. $(2012 \mathrm{a}, \mathrm{b})$ in conjunction with our analyses of the tidalfluvial water-level regime to identify reach boundaries representative of both hydrologic processes and the distribution of vegetation.

\section{Methods}

\section{Water-Level Data Collection and Processing}

Most of the water-level, river flow, and atmospheric records on which our analysis is based cover a 21-year period, 19912011, slightly more than one 18.6-year cycle of tidal nodalvariations. This period was chosen to represent the present in terms of hydrology and flow management. It also encompasses a wide range of river flow conditions, including winter floods in 1996 and 1997, spring freshets in 1997 and 2011 that were large by modern standards, and a very low-flow year in 2001 (one of the two lowest since 1878). Data from nine tide gauges and one pressure gauge located near the thalweg were available during part or all of this period. To improve spatial coverage, less complete 1980-1989 tide data from nine other tide gauges were also included. Water-level analyses, in the form of regression models and inundation history estimates, were carried out for these 19 stations (Fig. 1 and Table 1; hereafter, the channel stations). To relate channel processes to wetland vegetation patterns, water-level data collected 2005-2010 through 36 pressure-gauge deployments (12 years duration) at floodplain wetland stations (hereafter the floodplain or wetland stations) were analyzed; see Table electronic supplementary material (ESM)-1 for location information. The statistical properties of water levels at the channel stations were combined with the wetland station data to hindcast 21-year water-level properties at the 23 wetland stations listed in Table 2. The ESM and Part I provide further details regarding the channel and wetland station data and data processing, including correction of vertical positioning errors for the wetland gauges, where reference levels were difficult to establish.

The description of tidal-fluvial interactions provided below is based on analyses of the water-level response to tidal, fluvial, and coastal (upwelling and downwelling) forcing, as reflected in the daily variations of three tidal water-level descriptors: LLW, MWL, and HHW. Time series of daily values of these properties were extracted from hourly tidal records (interpolated to $6 \mathrm{~min}$ ). HHW and LLW were the extrema within each $25 \mathrm{~h}$ period, centered at noon. MWL was determined as the noon water level in a low-pass filtered version of the water level from each station. The Cosine filter used had a length of $185 \mathrm{~h}$ and removed all tidal variations.

For regression analyses, data from all stations were vertically referenced to the Columbia River Datum (CRD) above rkm-39 and to mean LLW (MLLW) seaward of this point. CRD was determined by the US Army Corps of Engineers in 1913 to be the approximate low-water plane along the river for the lowest flow levels. Aside from correction of errors in a few locations after World War II, CRD has not been adjusted for 
Table 1 Channel stations

\begin{tabular}{|c|c|c|c|c|c|c|c|}
\hline Station & Source & Rkm & Zone/Reach ${ }^{\mathrm{a}}$ & Dates & LOR, h & $\% \operatorname{good}$ & CRD on NAVD88, $\mathrm{m}$ \\
\hline North Jetty & NOS & 2.6 & $\mathrm{E}$ & 1982 & 3480 & 100 & -0.21 \\
\hline Jetty A & NOS & 4.5 & $\mathrm{E}$ & 1981 & 5470 & 100 & 0.171 \\
\hline Ft Stevens & NOS & 13.2 & LE & 1981 & 5424 & 100 & -0.143 \\
\hline Hammond & NOS & 14 & LE & 2011-2012 & 13584 & 100 & -0.137 \\
\hline Hammond & NOS & 14.5 & LE & 1982-1989 & 59496 & 89.1 & -0.13 \\
\hline Knappton & NOS & 24 & EM & 1981 & 5138 & 94 & -0.01 \\
\hline Tongue $\mathrm{Pt}$ & NOS & 29 & EM & 1991-2012 & 192864 & 100 & -0.182 \\
\hline Altoona & NOS & 39 & UE & 1981 & 5040 & 100 & 0.149 \\
\hline Skamokawa & $\operatorname{NOS}^{\mathrm{b}}$ & 54 & UE & 1991-2012 & 192864 & 94.3 & 0.273 \\
\hline Wauna & $\mathrm{NOS}^{\mathrm{b}}$ & 67 & UE & 1991-2012 & 192864 & 95.8 & 0.442 \\
\hline Beaver $^{\mathrm{c}}$ & USGS & 87 & LTR & 1991-2012 & 192864 & 36.9 & 0.63 \\
\hline Longview & $\mathrm{NOS}^{\mathrm{b}}$ & 106 & LTR & 1991-2012 & 192864 & 96.4 & 0.88 \\
\hline St Helens & $\mathrm{NOS}^{\mathrm{b}}$ & 139 & MTR & 1991-2012 & 192864 & 94.8 & 1.262 \\
\hline Columbia Slough & USGS & 154 & MTR & 1991-2012 & 192864 & 92.0 & 1.336 \\
\hline Vancouver & $\operatorname{NOS}^{\mathrm{b}}$ & 171 & MTR & 1991-2012 & 192864 & 95.7 & 1.63 \\
\hline Washougal $^{\mathrm{d}}$ & USGS & 195.5 & MTR & 1981 & 8760 & 75.1 & 2.14 \\
\hline Reed Island & PNNL & 198 & UTR & 2007-2009 & 19248 & 91.2 & 2.19 \\
\hline Multnomah & USGS & 219 & UTR & $1980-1981$ & 17544 & 64.3 & 2.69 \\
\hline Warrendale $^{\mathrm{f}}$ & USGS & 229.3 & UTR & $1980-1988$ & 2763 days & $93.7^{\mathrm{b}}$ & 3.00 \\
\hline Bonneville & USGS & 233 & $\mathrm{C}$ & 1991-2012 & 192864 & 99.8 & 3.59 \\
\hline
\end{tabular}

LOR length of record

${ }^{\mathrm{a}}$ Zones and reaches are shown in Fig. 1

${ }^{\mathrm{b}}$ NOS was responsible for data collection for these stations since their installation in 1986, but data archiving before 27 March 2002 was carried out by the US Army Corps of Engineers, North Pacific Division

${ }^{\mathrm{c}}$ Data before 1 October 2004 were not used, because the datum was uncertain

${ }^{\mathrm{d}}$ Although Washougal data passed initial quality control checks, Washougal regression results were inconsistent with other nearby stations and, therefore, rejected

${ }^{\mathrm{e}}$ Pressure gauge

${ }^{\mathrm{f}}$ Warrendale is tabulated in terms of days, because compilations of LLW, MWL, and HHW water were used; hourly data are not available for most years

changing bathymetry and river flow. In general, water levels have, for any given flow, dropped since 1913 due to navigational development and reduced sediment supply (Jay et al. 2011), but minimum flows are higher, so CRD remains a useful datum, especially for inundation calculations. To understand the physical processes governing water-level variations, plots relative to a geodetic surface are more useful, for which purpose NAVD88 (North American Vertical Datum 1988) is used (see Table 1 for elevations of CRD relative to NAVD88). The National Ocean Service adjusts MLLW periodically, and all tide data seaward of rkm-39 were adjusted to the most recent (1983-2001) tidal epoch (http:// tidesandcurrents.noaa.gov/station retrieve.shtml?type $=$ Datums). An inverse-barometer effect correction was made to all water-level values before they were used in regression models. For this purpose, sea level pressure data from a nearby coastal station at Newport, OR (at $44.6^{\circ} \mathrm{N}$ ) were used.

\section{Modeling Tidal-Fluvial Interactions}

\section{River Tides and Datums—Practical Regression Models}

Regression models are used here to determine the response of water levels to external forcing by tides, river flow, coastal processes, and power-peaking. The water levels modeled, for both channel and wetland stations, are LLW, MWL, and HHW. In a tidal river, water levels are too non-stationary to be usefully described by longterm means (e.g., by the usual MLLW chart datum). Rather, they need to be described in terms of their response to external processes. The modeling approach used here was developed by Jay and Flinchem (1997), Kukulka and Jay (2003a, b) and Jay et al. (2011). It is based on a theory of tidal propagation in convergent, frictional channels (Jay 1991). Tidal propagation under these circumstances can be described in terms of a single (incident) wave - the reflected wave is insignificant 
Table 2 Floodplain Stations used in Modeling LLW, MWL, and HHW

\begin{tabular}{|c|c|c|c|c|c|c|c|c|c|}
\hline $\mathrm{Rkm}$ & Wetland names & Zone/Reach ${ }^{\mathrm{a}}$ & Deployed & Retrieved & LOR (days) & $\%$ good & $\begin{array}{l}\text { Mean } \\
\text { elevation } \\
\mathrm{m}, \mathrm{CRD}\end{array}$ & $\begin{array}{l}\text { Datum } \\
\text { correction, } \\
\mathrm{m}^{\mathrm{b}}\end{array}$ & $\begin{array}{l}\text { Reference station } \\
\text { and comments }\end{array}$ \\
\hline 12 & Chinook River & LE & $8 / 17 / 2008$ & $8 / 18 / 2009$ & 365 & 100 & $1.9-2.3$ & 0.06 & Tongue $\mathrm{Pt}$ \\
\hline 24 & Walluski River & LE & $6 / 5 / 2008$ & $6 / 28 / 2009$ & 389 & 100 & ND & 0 & Tongue $\mathrm{Pt}$ \\
\hline 35 & Secret River & EM & $7 / 30 / 2007$ & $7 / 2 / 2008$ & 338 & 100 & $1-2$ & -0.13 & Tongue Pt \\
\hline 39 & Crooked Creek & EM & $5 / 2 / 2005$ & $4 / 52007$ & 704 & 88.7 & ND & -0.07 & Tongue Pt \\
\hline 43 & Karlson Island & UE & $8 / 16 / 2007$ & $8 / 1 / 2008$ & 339 & 100 & 1.7 & -0.09 & Skamokawa \\
\hline 53 & Welch Island & UE & $7 / 20 / 2008$ & $8 / 3 / 2009$ & 379 & 100 & 1.6 & 0 & Skamokawa \\
\hline 61 & Ryan Island & UE & $7 / 23 / 2009$ & $8 / 10 / 2010$ & 383 & 100 & 1.9 & 0.2 & Wauna \\
\hline 62 & Bradwood Slough & UE & $7 / 23 / 2009$ & $8 / 10 / 2010$ & 383 & 96.5 & ND & 0.2 & Wauna \\
\hline 73 & Westport Slough & UE & $8 / 18 / 2009$ & 7/9/2010 & 326 & 100 & ND & -0.09 & Wauna \\
\hline 80 & Clatskanie River & UE & $8 / 18 / 2008$ & $7 / 24 / 2009$ & 340 & 100 & 2 & -0.33 & Beaver \\
\hline 98 & Coal Creek & UE & $7 / 20 / 2008$ & $8 / 8 / 2009$ & 384 & 99.2 & ND & -0.3 & Longview \\
\hline 100 & Lord Island & LTR & $8 / 18 / 2008$ & $7 / 21 / 2009$ & 337 & 100 & 1.5 & -0.31 & Longview \\
\hline 113 & Cottonwood Island & LTR & $3 / 12 / 2009$ & $8 / 12 / 2010$ & 518 & 100 & 1.4 & -0.02 & Longview \\
\hline 131 & Goat Island & LTR & $8 / 18 / 2008$ & 8/9/2009 & 356 & 100 & 1.5 & 0 & St Helens \\
\hline 141 & Gee Creek & MTR & $8 / 10 / 2009$ & $7 / 24 / 2010$ & 348 & 90 & ND & -0.2 & St Helens \\
\hline 143 & Scappoose Bay & MTR & $7 / 26 / 2009$ & $7 / 26 / 2010$ & 366 & 99.7 & 1.3 & -0.1 & St Helens \\
\hline 154 & Sauvie Cove & MTR & $7 / 25 / 2009$ & $7 / 28 / 2010$ & 368 & 100 & 1.5 & -0.17 & $\begin{array}{l}\text { St Helens and } \\
\text { Col Slough }\end{array}$ \\
\hline \multirow[t]{2}{*}{191} & \multirow[t]{2}{*}{ McGuire Island } & \multirow[t]{2}{*}{ MTR } & $7 / 19 / 2006$ & $6 / 22 / 2007$ & 338 & 95 & 1.5 & Not used & $\begin{array}{c}\text { Gauge sank during } \\
\text { the deployment }\end{array}$ \\
\hline & & & $9 / 19 / 2008$ & $9 / 19 / 2009$ & 364 & 100 & 1.5 & multiple & $\begin{array}{l}\text { A ramp, then three } \\
\text { offsets; Reed Is }\end{array}$ \\
\hline 196 & $\begin{array}{l}\text { Current Sandy } \\
\text { River Mouth }\end{array}$ & UTR & $9 / 20 / 2008$ & $9 / 19 / 2009$ & 364 & 100 & ND & 0.14 & $\begin{array}{l}\text { A ramp, then }+0.14 \\
\text { Reed Is }\end{array}$ \\
\hline \multirow[t]{2}{*}{203} & \multirow[t]{2}{*}{ Highway 84} & \multirow[t]{2}{*}{ UTR } & \multirow[t]{2}{*}{ 9/20/2008 } & \multirow[t]{2}{*}{$9 / 22 / 2009$} & \multirow[t]{2}{*}{368} & \multirow[t]{2}{*}{99.9} & ND & & $\begin{array}{l}\text { Reed Island; } \\
\quad \text { first } 2471 \mathrm{~h}, 0.0 \text {; }\end{array}$ \\
\hline & & & & & & & ND & Up to 0.25 & Ramp after first $2471 \mathrm{~h}$ \\
\hline 211 & Sand Island (Rooster Rock) & UTR & $7 / 24 / 2008$ & $7 / 26 / 2009$ & 368 & 99.9 & 1.1 & 0.15 & Reed Is. \\
\hline 221 & Franz Lake & UTR & $7 / 22 / 2008$ & $7 / 28 / 2009$ & 371 & 100 & 1.9 & 0.63 & Reed Is and Bonneville \\
\hline 230 & Hardy Creek & $\mathrm{LC}$ & $7 / 23 / 2008$ & $7 / 26 / 2009$ & 368 & 100 & ND & 0.37 & Reed Is and Bonneville \\
\hline
\end{tabular}

$N D$ no data

${ }^{\mathrm{a}}$ Zones and reaches are shown in Fig. 1

${ }^{\mathrm{b}}$ The datum correction is the amount added to the data to yield HHW water values matched to a nearby channel station

except near reflecting barriers. The background for these models is described in the ESM.

We employ, as described in the on-line supplement or ESM, regression models (equations ESM-3 to ESM-5, repeated here for convenience), of the form:

$$
\begin{aligned}
& \mathrm{LLW}=\mathrm{a}_{0 k}+\mathrm{a}_{1 \mathrm{k}} \mathrm{Q}_{\mathrm{B}}{ }^{m_{1}}+\mathrm{a}_{2 \mathrm{k}} \mathrm{Q}_{\mathrm{WR}}^{{ }^{n_{1}}}+\mathrm{a}_{3 \mathrm{k}} \mathrm{CUI} \\
& +\mathrm{a}_{4 \mathrm{k}}\left(\frac{\mathrm{T}_{R, \mathrm{H}}^{\mathrm{S}_{1}}}{\left(1+\mathrm{Q}_{\mathrm{B}}+\mathrm{Q}_{\mathrm{WR}}\right)^{r_{1}}}\right) \\
& \mathrm{HHW}=\mathrm{b}_{0 \mathrm{k}}+\mathrm{b}_{1 \mathrm{k}} \mathrm{Q}_{\mathrm{B}}{ }^{m_{2}}+\mathrm{b}_{2 \mathrm{k}} \mathrm{Q}_{\mathrm{WR}}^{{ }^{n_{2}}}+\mathrm{b}_{3 \mathrm{k}} \mathrm{CUI} \\
& +\mathrm{b}_{4 \mathrm{k}}\left(\frac{\mathrm{T}_{R, \mathrm{H}}^{\mathrm{s}_{2}}}{\left(1+\mathrm{Q}_{\mathrm{B}}+\mathrm{Q}_{\mathrm{WR}}\right)^{\mathrm{r}_{2}}}\right)
\end{aligned}
$$

$$
\begin{aligned}
\mathrm{MWL}= & \mathrm{c}_{0 \mathrm{k}}+\mathrm{c}_{1 \mathrm{k}} \mathrm{Q}_{\mathrm{B}}^{m_{3}}+\mathrm{c}_{2 \mathrm{k}} \mathrm{Q}_{\mathrm{WR}}^{{ }^{n_{3}}}+\mathrm{c}_{3 \mathrm{k}} \mathrm{CUI} \\
& +\mathrm{c}_{4 \mathrm{k}}\left(\frac{\mathrm{T}_{R, \mathrm{H}}^{\mathrm{s}_{3}}}{\left(1+\mathrm{Q}_{\mathrm{B}}+\mathrm{Q}_{\mathrm{WR}}\right)^{r_{3}}}\right)
\end{aligned}
$$

Where:

$Q_{\text {B }} \quad$ daily mean Columbia flow at Bonneville Dam or Beaver, $1000 \mathrm{~s}$ of $\mathrm{m}^{3} / \mathrm{s}$

$Q_{\mathrm{WR}} \quad$ daily mean Willamette flow at Portland, 1000s of $\mathrm{m}^{3} / \mathrm{s}$

$T_{R, \mathrm{H}} \quad$ greater diurnal tidal range (GDTR, $\mathrm{m}$ ), or HHW-LLW, at Hammond

CUI daily Coastal Upwelling Index, in $10 \mathrm{~m}^{2} \mathrm{~s}^{-1}$, positive for upwelling (Bakun 1973). 


\section{$a_{i k}$ to $c_{i k}$, regression parameters for each station and $i=0,3 \quad$ model \\ $k \quad$ index for channel stations, $k=1,19$ \\ $\left\{s_{1}, s_{2}, s_{3}\right\} \quad$ tide-flow interaction exponent; varies with location and model \\ $\left\{m_{1}, m_{2}, \quad\right.$ Columbia flow exponent; varies with location \\ $\left.m_{3}\right\} \quad$ and model \\ $\left\{n_{1}, n_{2}, n_{3}\right\} \quad$ Willamette flow exponent; varies with location and model \\ $\left\{r_{1}, r_{2}, r_{3}\right\} \quad$ second tide-flow interaction exponent; varies with location and model}

Interpretation of the terms in (1) to (3) is discussed in the ESM; tables of exponents and regression-model coefficients are also provided. Briefly, the first three terms on the right in each of (1) to (3) relate MWL, HHW and LLW to datum and system geometry (with coefficients $a_{0 \mathrm{k}}, b_{0 \mathrm{k}}, c_{0 \mathrm{k}}$ ), and river flows (coefficients $a_{1 \mathrm{k}}, b_{1 \mathrm{k}}, c_{1 \mathrm{k}}$ and $a_{2 \mathrm{k}}, b_{2 \mathrm{k}}, c_{2 \mathrm{k}}$ ). The fourth term on the right in each of (1) to (3) represents the effects of coastal upwelling via the CUI. The last term in (1) to (3) represents the effects of the nonlinear interaction of tides and river flow. Other systems might require a different set of forcing variables, e.g., wind or coastal sea level in place of CUI.

The coefficients $a_{i k}$ to $c_{i k}(i=0,3, k=1,19)$ in (1) to (3) were determined by robust multiple linear regression analyses (Huber 1996; Leffler and Jay 2009) to best fit the observations, with a different set of coefficients and exponents determined for each station. A robust regression iteratively downweights outlier points, to achieve a better regression solution with tighter confidence limits. One departure from robust linear regression was used. Extremes of tidal range and river flow are rare, but these data are vital in determining the behavior of tidal datums for extreme forcing conditions. Thus, data points were weighted by an analytical function that approximated the inverse square root of their frequency of occurrence. This weighting was applied along with the robust weighting, so that the total weight on each data point in each iteration was the product of the river flow/range weight with the robust weight. A neural network model (e.g., Hidayat et al. 2014) might provide hindcasts of equal or greater accuracy than produced by the above regression models, however, we prefer a simpler, more physics-based approach.

\section{Inundation Hindcasts, 1991-2011}

Of the 19 channel stations, tidal data were complete for 19912011 only for Tongue Pt. In contrast, forcing data (Hammond tidal range, Bonneville and Willamette river flows, and CUI) were almost complete for 1991-2011, though a few short gaps in CUI were interpolated. To provide a complete time series of tidal properties at the mainstem channel stations, the regression models described above were used to hindcast a uniform 1991-2011 time series of daily values of LLW, HHW, and MWL. These hindcast time series of LLW, MWL, and HHW were compiled into water-surface elevation-frequency and cumulative elevation-frequency plots (see the ESM for details).

Similar 1991-2011 hindcasts were made for floodplain stations throughout the river, to understand along-channel variation of floodplain inundation. The models for these stations are based on the mainstem channel stations. That is, the values of exponents $m_{i}, n_{i}, s_{i}$, and $r_{i}$ in (1) to (3) at each floodplain station are based on values at a nearby mainstem channel station. At many of the floodplain stations, however, it was necessary to use a minimum (a "floor") for LLW (the wetland channel bed elevation), below which LLW was not allowed to fall.

\section{Forcing Data, 1991-2011}

Regression models require forcing data, in this case, the CUI, Hammond tidal range $\left(T_{\mathrm{R}, \mathrm{H}}\right)$ and river flow $Q_{\mathrm{B}}$ and $\mathrm{Q}_{\mathrm{WR}}$ (Fig. 2). Daily CUI (in $\mathrm{m}^{2} \mathrm{~s}^{-1}$ ) and details regarding the calculation methodology are available from: www.pfeg. noaa.gov/products/PFEL/modeled/indices/upwelling/. CUI values at $45^{\circ} \mathrm{N}$ and $48^{\circ} \mathrm{N}$ were interpolated to $46^{\circ} \mathrm{N}$ (near the mouth of the Columbia River). CUI is asymmetric, with the negative winter (downwelling) values being larger in magnitude (down to $-0.8 \mathrm{~m}^{2} \mathrm{~s}^{-1}$ ) and more irregular than the summer positive values that are uniformly $<0.3 \mathrm{~m}^{2} \mathrm{~s}^{-1}$. $T_{\mathrm{R}, \mathrm{H}}$ was predicted using robust $\mathrm{T}_{-}$Tide (Pawlowicz et al. 2002; Leffler and Jay 2009) from Hammond 1982-1989 data. Hammond was used because it is the station closest to the ocean that has sufficient length of record to provide good predictions; predictions were used, because no data are available for 1989-2011. $T_{\mathrm{R}, \mathrm{H}}$ shows winter and summer maxima in most years, and greater and lesser spring and neap tides each month.

Columbia River flows at Bonneville Dam (http://www. nwd-wc.usace.army.mil/perl/dataquery.pl) range from about 2 to $16 \times 10^{3} \mathrm{~m}^{3} \mathrm{~s}^{-1}$, with the highest flows in spring, notably in 1997 and 2011. Winter freshets may also increase mainstem flows, with winter flows in 1996, 1997, 2002, and 2011 being larger than many of the spring freshets that are now attenuated by flow regulation. Willamette River flows (http://waterdata. usgs.gov/usa/nwis/uv?site_no=14211720) are consistently low in summer, with a minimum of $\sim 150 \mathrm{~m}^{3} \mathrm{~s}^{-1}$. The highest Willamette River flows in winter are sporadic and follow major storms and/or snow-melt events. The snowmelt flood of February 1996 reached $11.9 \times 10^{3} \mathrm{~m}^{3} \mathrm{~s}^{-1}, 35 \%$ above the second largest flood event in early 1997, which was also caused by snowmelt. The 1996 flood was the largest since 1964, and the winter of 1995-1996, like the winter 
Fig. 2 Forcing functions used in regression models: CUI, Hammond greater diurnal tidal range $\left(T_{\mathrm{R}, \mathrm{H}}\right)$, Columbia River daily flow $\left(\mathrm{Q}_{\mathrm{B}}\right)$ at Bonneville Dam (top left), and Willamette River daily flow $\left(\mathrm{Q}_{\mathrm{WR}}\right)$ at Portland (top right), all for 1991-2011, inclusive
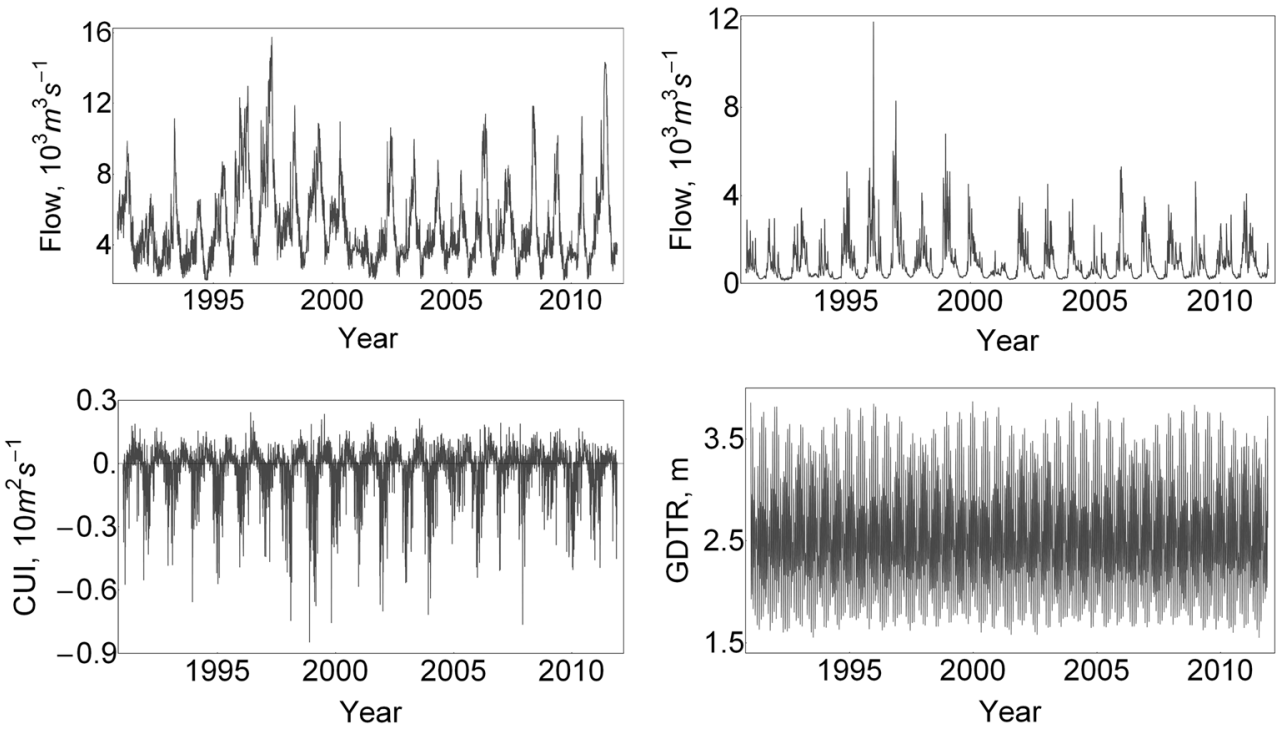

of 1964-1965, was notable for having two large winter floods, such that the spring freshet in the Columbia was not as large as could have been expected for a winter with such a large snow pack. Forcing data from the same sources (not shown here) were used to force the regression models for the 1980 s data.

\section{Vegetation and Sum Exceedance Value Analysis}

We examined the quantitative relationship between the waterlevel regime and the distribution of herbaceous, shrubdominated and forested wetlands. Specifically, water-level data and plant species elevations were collected in 54 tidal wetlands over the period 2007-2012. We calculated the spatially average elevation (on CRD) of wetlands using data from $>3,400$ vegetated plots on which we also collected herbaceous plant species and cover data following the methods in Roegner et al. (2009). To compare the analysis of forcing factors in the LCRE to the site-scale hydrologic regime, we modified a sum exceedance value (SEV) index of hydrologic conditions previously developed to quantify hydrologic effects on plant distribution (Gowing and Spoor 1998). The modified SEV is calculated as:

$\mathrm{SEV}=\sum_{i=1}^{n} h_{\mathrm{elev}}$

where $n$ is the number of hours present in the growing season (4/22 to $10 / 12)$ and $h_{\text {elev }}$ is the hourly water depth over the average elevation of wetland vegetation (Borde et al. 2012a, b). Data may be from pressure gauges located at wetland stations, other nearby locations, or models, as described below.

The SEV is an integrative measure. Its seasonal integration largely averages out differences between wetland and channel tides related to wave distortion and other nonlinearities. For SEV calculations in the strongly tidal part of the system, hourly data are mandatory to capture water level variations correctly. Likewise, the growing season was assumed to extend from April 22 to October 12 at all stations based on NRCS (2002). However, due to missing data in some records, the full growing season could not be used in (4) for most stations. Instead, $h_{\text {elev }}$ records were summed over the periods $4 / 22$ to $6 / 21$ and $8 / 20$ to $10 / 12$ for each available year and station. However, 16 wetland pressure-gauge records were complete, allowing calculation of the SEV for the full growing season; we denote these by fSEV. Where continuous records ended in July or August, records from the late summer and early fall from the previous year were used; this is the season with the lowest river flows and the least effect of storms.

We used a generalized linear model on $\log _{10} \mathrm{SEV}$ as a function of the reach, with water year as a covariate, and Tukey's pair-wise comparison to examine whether SEVs differ by vegetation zone. We used ANOVA and Tukey's pair-wise comparison to examine whether vegetation data (the average absolute percent cover and average total plant species richness for wetland study sites) differ by vegetation zone. We also used a linear regression of the SEV on wetland elevation to further examine the river reaches listed above, with the exception of the most seaward, salinity-intruded reaches.

SEV data, calculated using data from wetland stations, are limited in spatial coverage and not available for any extreme low-flow years. However, as demonstrated in Part I and discussed below, wetland water-level distributions are closely related to channel water-level distributions, aside from the truncation of minimum water level at wetlands with minimum elevations above LLW. For modeling purposes, a potential SEV (denoted by pSEV) was, therefore, calculated from hourly water-level data at each channel tide gauge for the growing season for the entire 1991 to 2011 period. To provide information relevant to 
wetlands at various elevations, pSEV was tabulated for each year and station, relative to a series of base elevations (at $0.1 \mathrm{~m}$ intervals) from $-0.5 \mathrm{~m}$ to $7.5 \mathrm{~m}$ on CRD (or MLLW). These elevations were chosen to encompass the full range of wetland elevations and water levels throughout the system. These pSEVs indicate (at least for wetlands close to the CR mainstem thalweg) what SEV would have been observed for a hypothetical wetland at each elevation and along-channel position for each year, though wetlands (including emergent marsh, shrub, and forested wetlands) currently span only $+0.5 \mathrm{~m}$ to $5.5 \mathrm{~m}$ on CRD in the LCRE (Borde et al. 2011). Also, pSEVs differ from SEVs because of the $6 / 22$ to $8 / 20$ gap in the SEV calculations. The more complete channel tide gauge records eliminate the need for this gap in pSEV estimates.

The pSEV metric allows analysis of SEV properties over the entire 1991 to 2012 time period considered here and for all possible marsh elevations, but it is important to focus on pSEVs at typical wetland elevations. Thus, pSEVs were determined for typical marsh elevations, which vary along-channel. To determine the relevant elevation, a fifth-order polynomial in half-powers of $x(\mathrm{rkm})$ from $x^{0}$ to $x^{2.5}$ was fit to marsh elevations (as the dependent variable) with rkm as the independent variable. There were too few shrub and forested wetlands sampled to determine typical elevations along-channel for these marsh types. Because shrub and forested wetlands are generally higher (where present) than marshes, pSEVs and the interannual variability of pSEV will be lower in shrubs and forested wetlands than in marshes. Finally, growingseason mean values of LLW, MWL, and HHW were calculated at each channel station for the growing season over the 1991-2012 period. Further details of the pSEV calculation are given in the Supplementary Material.

\section{Results}

As noted in Part I: "(t)idal-fluvial water levels in the LCRE are nonlinear, non-stationary, and influenced by a number of factors - astronomical tidal forcing, spatially variable channel width and depth, the presence (or absence) of peripheral intertidal areas, river flow, coastal processes (primarily upwelling, and downwelling), and power-peaking." To understand how water-level properties relate to peripheral floodplain ecosystems (e.g., vegetation properties), we describe and summarize waterlevel variations at mainstem channel and floodplain wetland stations in three ways: (a) with regression models of water levels based on the dynamics of tidal-fluvial systems, (b) through 21-year hindcasts of inundation, and (c) through analysis of wetland and floodplain fSEVs in relation to other hydrologic properties.

\section{Along-Channel Variations: Regression Models}

\section{An Overview}

The responsiveness of the system to external forcing is reflected in the exponents in the channel station regression models (1) to (3), shown in Fig. 3a. The exponents $m_{k}$ for Bonneville (or Beaver flow) are 0.8 from Beaver seaward and maximal (1.4-1.5) between rkm-139 and 195, covering most of the theoretical range of 0.5 to 1.5 (Kukulka and Jay 2003a). Thus, the maximal response to flow fluctuations occurs in the tidal river between Beaver (rkm-87) and Washougal (rkm-198) where, as shown below, tidal range responds most strongly to flow variations. Note that Beaver flow includes Willamette River flow and is used from Longview (rkm-106) seaward, so the exponents $n_{i}$ for Willamette River flow are only used landward from rkm107, where they are $0.8-1.2$. The highest values of $n(1-1.2)$ are for HHW near the Willamette-Columbia confluence (rkm154). Landward of this confluence, where the influence of the Willamette is less direct, the $n_{i}$ are smaller. The exponents $s_{k}$ for tidal range vary from 1.4 to 2 relative to a theoretical value of 2 , but their spatial patterns are different for the three water levels modeled. The exponents $r_{i}$ are consistently $<1$, varying from 0.5 to 0.8 ; this is close to the theoretical value of 0.5 for tidal constituents (Kukulka and Jay 2003a).

The success of the regression models can be judged by the adjusted squared error $\left(R^{2}\right)$ values and RMS (root mean square) residual errors in Fig. 3b. Residuals (hindcastobserved) and RMS errors were calculated for the 19912011 channel stations and all floodplain stations. There is a trend toward larger RMS error at upriver stations (both channel and floodplain) that reflects the greater variance at these stations (cf. Part I). Overall, the smallest RMS errors are for MWL, which has the lowest variance. Channel RMS errors for LLW, MWL, and HHW were $<0.21 \mathrm{~m}$ except at Bonneville, where they were $0.30,0.24 \mathrm{~m}$, and $0.34 \mathrm{~m}$, respectively. Below Reed Island, RMS errors for LLW and MWL did not exceed $0.19 \mathrm{~m}$. Errors for HHW are somewhat larger, because HHW is the water level exhibiting the highest variability. There was also some negative skewness in the predictions (observed values $>$ predicted), especially for the rare excursions of HHW during floods. RMS errors for the floodplain stations (Fig. 3b) are irregular (due to local topography and perhaps to local tributary inflow) and sometimes larger than for the channel stations. This is probably because the wetland records were very short, so that the exponents in the floodplain station regression models had to be taken from neighboring channel stations. RMS errors for LLW and MWL are sometimes lower at floodplain than at channel stations, reflecting the fact that the truncation of low waters by relatively higher wetland channel elevations reduces variability of both LLW and MWL. 
a)
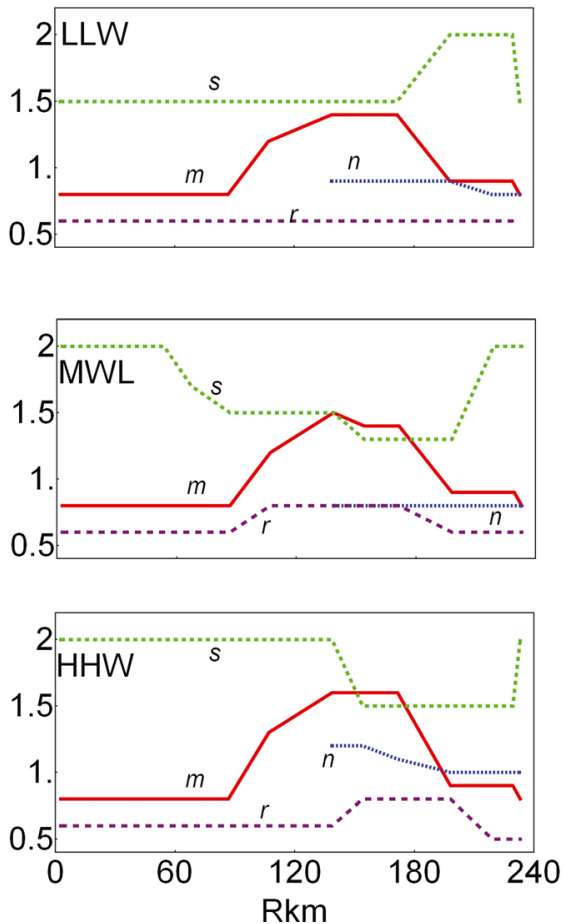

Fig. 3 a Channel model parameters as a function of along-channel distance; floodplain models used the same parameters as a neighboring channel model. Parameters $m, n, s$, and $r$ are as used in (1)-(3), and their values are determined by iterative regression. $\mathbf{b}$ Channel and floodplain

The weighted $R^{2}$ values for models of LLW, HHW, and MWL using (1) to (3) were 0.82 to 0.99 for channel stations from Beaver landward, but lower further seaward (Fig. 3b). The lowest $R^{2}$ values for channel stations were for MWL below rkm-50, for two reasons. First, the dynamic range of estuarine water-surface elevations (especially MWL) is quite small, so noise (primarily processes not considered here) plays a larger role than in the tidal river. Also, the coastal ocean does not conform to the model assumption that the time scales of system adjustment are comparable to those of the forcing; thus, MWL at stations in the lower estuary may integrate forcing over longer time periods. Despite low RMS errors, low $R^{2}$ values for LLW at some of the floodplain stations reflect the role of topography in that most low tides reach a minimum lower than wetland slough bed elevation, so that variability of LLW is low, and observed variations in LLW are largely determined by local factors not represented in the regression models, e.g., seasonal changes in vegetation or movement of woody debris. Detailed regression analysis properties and results for Vancouver HHW are shown in Figure ESM-1, as an example.

\section{River Flow and Tidal Range Effects on Water Levels}

Regression model results provide an overview of the systemwide water-level response to important forcing factors, including model RMS error (m) and adjusted $R^{2}$ for hindcasts based on (1)-(3) for the 1991-2011 period. Channel RMS error can only be plotted for the 10 stations with data in the 1991-2011 period

river flow, tidal range, atmospheric pressure and power-peaking. Figure 4 shows the effects of changes in Hammond tidal range and river flow on HHW, MWL, and LLW for six combinations of Columbia River (at Bonneville) and Willamette River (at Portland) flows. The maximum (daily average) Bonneville flow level modeled $\left(13,000 \mathrm{~m}^{3} \mathrm{~s}^{-1}\right)$ is less than half of the historical maximum flow $\left(\sim 35,000 \mathrm{~m}^{3} \mathrm{~s}^{-1}\right)$, but spring flow reduction due to the reservoir system irrigation diversion greatly limited 1980 2011 flows on which the model is based. Although small relative to the historical range of flows, the modeled range represents typical modern, managed flow conditions.

High water levels occur during high-flow periods at upriver stations, up to 11 m NAVD88 at Bonneville (rkm-233); in contrast, water levels below Wauna at rkm-67 are little affected by high flows. Increases in Willamette River flow illustrate a backwater effect (Fig. 4, compare the bottom two panels), especially at Vancouver (rkm-171) and Reed Island (rkm-198). The very sharp increase in surface slope landward of Warrendale (rkm229) reflects the extremely rough stream bed in this area, related to the presence of landslide debris from the bridge of the gods event that occurred ca. 1450 (O'Connor 2004).

Greater diurnal tidal range $\left(T_{\mathrm{R}}=\mathrm{HHW}-\mathrm{LLW}\right)$ is largest in the lower estuary between Ft Stevens (rkm-14.5) and Tongue $\mathrm{Pt}$ (rkm-29) for all flow levels. This reflects amplification of $\mathrm{M}_{2}$ (but not $\mathrm{K}_{1}$ ) in the lower estuary (see Part I). This weak resonance is likely due to: (a) the change in channel width 
landward of Tongue Pt, and (b) reduced bed stresses in the estuary caused by density stratification (Giese and Jay 1989). As flows increase, tidal ranges contract markedly at upriver stations, but much less so in the estuary.

Effects of flow variations on the tidal range are subtle below Beaver, while at more landward stations, high flows greatly reduce tidal range and also suppress neap-spring variability. To represent neap and spring tides, we varied the forcing tidal range $\left(T_{R}\right)$ at Hammond by $\pm 0.5 \mathrm{~m}$ (Fig. 4). Because actual tidal monthly variation is related to the phase differences between the diurnal $\left(\mathrm{D}_{1}\right)$ and semidiurnal $\left(\mathrm{D}_{2}\right)$ tides as well as their individual amplitudes, Fig. 4 does not fully capture neapspring effects. Nonetheless, regression model results can be used to understand neap-spring variability in the system in relation to river flow variations. At Vancouver, for example, tidal range may vary by an order of magnitude seasonally for any given ocean tidal forcing. The average river slope (i.e., the slope of the MWL surface) also varies with flow and tidal range. For low to average Bonneville flows $(2,500$ and $\left.6,000 \mathrm{~m}^{3} \mathrm{~s}^{-1}\right)$, neap-spring variability in MWL increases upriver of Beaver ( $\mathrm{rkm}-87)$ and reaches a maximum at Vancouver; this maximum moves downstream for higher flows. Neap-spring changes in MWL primarily reflect the fact that a greater river slope is needed to discharge the same flow on a spring tide than on a neap tide. Secondarily, the landward Stokes drift (Longuet-Higgins 1969) is larger on spring tides. There is, therefore, a correspondingly larger total non-tidal discharge, the sum of river flow and a compensation flow for the Stokes drift, on spring tides. Except during low-flow periods, the Stokes drift is small compared to the mean flow in the tidal river, and increased friction is the major factor increasing the slope and deepening the flow on spring tides.

\section{Coastal Effects on Water Levels}

The system response to changes in coastal processes can be determined by varying the CUI (Fig. 5). Estuarine and tidalriver stations up to Longview (rkm-106) show elevated water levels for downwelling conditions when coastal water levels are high (negative CUI), and lower water levels during periods of upwelling when coastal water levels are low (positive CUI). The response to CUI decreases in strength above Beaver (rkm-87) and then changes sign from St Helens landward with a very strong response between rkm-190 and 229, in the western Columbia River Gorge. Seasonal CUI variations are reflected in changes in coastal water level of up to $0.3 \mathrm{~m}$. The response in the broad midestuary is stronger at stations on the north side (e.g., at Knappton and Altoona, rkm-24 and 39, respectively) than on the south side (e.g., Tongue Pt, rkm-29). This likely reflects a correlation between downwelling conditions $(\mathrm{CUI}<0)$ and coastal winds to the north that push water to the north side of the estuary. However, the irregularity of the LLW and HHW water curves in Fig. 5 for estuarine stations also reflects the variable (and often short) LOR available for the estuarine stations from the 1980s.
Fig. 4 Modeled effects of changes in $T_{R}$ (Hammond greater diurnal tidal range) and river flow on HHW, MWL, and LLW for six combinations of $Q_{\mathrm{B}}(2.5,6,9.5$ and $13 \mathrm{k}$ (thousand) $\mathrm{m}^{3} \mathrm{~s}^{-1}$ ) and $Q_{\mathrm{WR}}\left(0.5,2\right.$, and $\left.4 \mathrm{k} \mathrm{m}^{3} \mathrm{~s}^{-1}\right)$. The solid lines indicate the system response for the base tidal condition $\left(T_{\mathrm{R}}=2.6 \mathrm{~m}\right.$ at Hammond), dotted/dashed lines indicate the effect of changing $\mathrm{T}_{\mathrm{R}}$ by $-0.5 /+0.5 \mathrm{~m}$, respectively; note the variable vertical scales. Vertical gray bars indicate $95 \%$ confidence limits; greater diurnal tidal range throughout the system is HHW-LLW
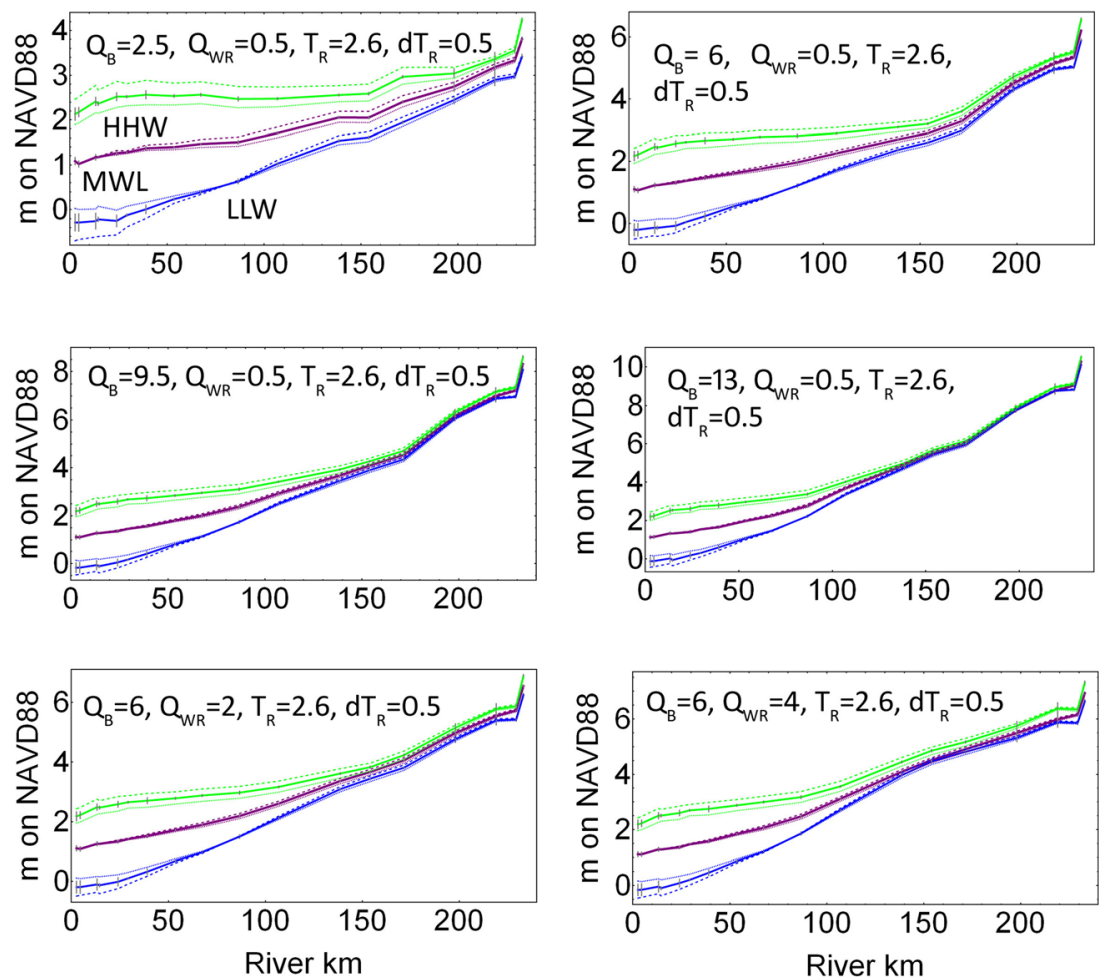


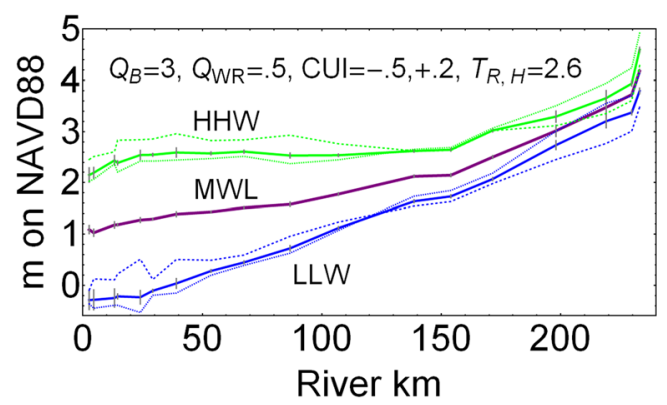

Fig. 5 Modeled effects of changes in CUI on HHW, MWL, and LLW for $Q_{\mathrm{B}}=3 \times 10^{3} \mathrm{~m}^{3} \mathrm{~s}^{-1}$ and $Q_{\mathrm{WR}}=0.5 \times 10^{3} \mathrm{~m}^{3} \mathrm{~s}^{-1}$. The solid lines indicate the system response for the base tidal condition $\left(T_{\mathrm{R}, \mathrm{H}}=2.6 \mathrm{~m}\right)$, dotted/dashed lines indicate the effect of changing CUI by $+0.2 /-0.5$ (in $10 \mathrm{~m}^{2} \mathrm{~s}^{-1}$ ), respectively. This choice of CUI variability reflects the observed variability; winter negative values show larger deviations from neutral conditions $(\mathrm{CUI}=0)$ than is the case for positive summer values. Vertical gray bars indicate $95 \%$ confidence limits; the choice of asymmetric changes in CUI reflects the asymmetry of the CUI distribution in Fig. 2. The large effect of CUI on water levels landward of rkm-200 is caused by drainage winds from the Columbia River Gorge that are correlated with CUI

\section{Power-Peaking Effects on Water Levels}

Power-peaking refers to the variable discharge (in this case at Bonneville Dam) caused by daily and weekly variations in hydropower production. Figure 6 shows the predicted power-peaking impacts on HHW and LLW for low and high Bonneville flows. MWL is assumed to be unaffected by power-peaking. The power-peaking in each case is assumed to be $\pm 500 \mathrm{~m}^{3} \mathrm{~s}^{-1}$, which is close to the median daily power-
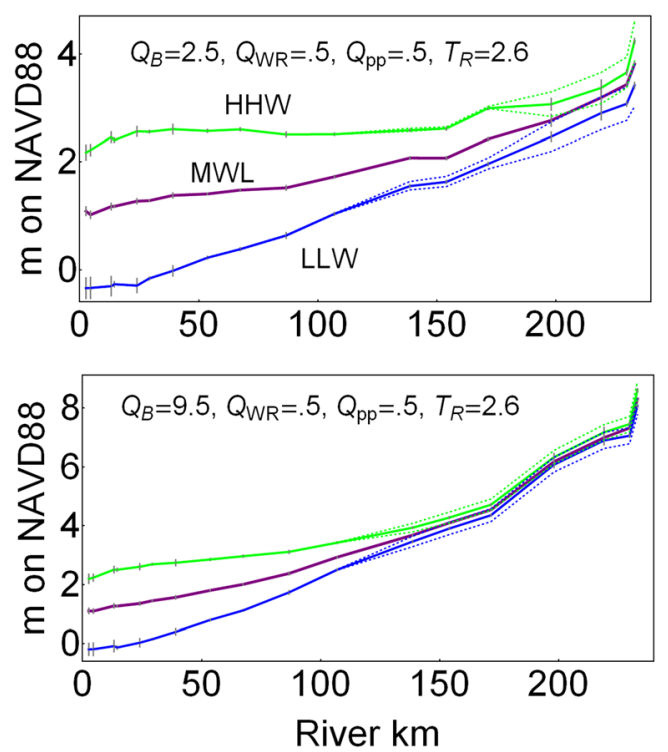

Fig. 6 Predicted daily power-peaking impacts on HHW and LLW (MWL assumed unaffected) for low and high Bonneville flows $\left(Q_{\mathrm{B}}=2.5\right.$ and $\left.9.5 \times 10^{3} \mathrm{~m}^{3} \mathrm{~s}^{-1}\right)$, with Willamette River at Portland flows $Q_{\mathrm{WR}}=0.5 \times 10^{3} \mathrm{~m}^{3} \mathrm{~s}^{-1}$. The power-peaking in both cases is $500 \mathrm{~m}^{3} \mathrm{~s}^{-1}$. Vertical gray bars indicate $95 \%$ confidence limits peaking amplitude. Power-peaking effects are strongest above Vancouver ( $\mathrm{rkm}-171)$, and most evident for low flows. Above rkm-200 or so, power-peaking accounts for almost all of the tidal range. Power-peaking effects are damped for high flow, but are still evident downstream to Longview (rkm-106) for all flow levels. LLW is in general more strongly affected than HHW. The $\mathrm{S}_{1}$ tidal constituent (period, $24 \mathrm{~h}$ ) is elevated (beyond values expected from astronomical forcing) all the way to the estuary. However, $\mathrm{S}_{1}$ amplitudes are $\leq 0.05 \mathrm{~m}$ below $\mathrm{rkm}-139$, so scarcely visible on the scale shown here.

\section{Inundation: 21-Year Hindcasts of LLW, MWL, HHW}

\section{Variations Along the Tidal-Fluvial Gradient}

Daily values of LLW, MWL, and HHW were hindcast for 1991-2011 for both channel stations and floodplain stations from (1) to (3) and forcing data (Fig. 2). The channel stations exhibit a regular change in tidal range (HHWLLW) and MWL along the tidal-fluvial gradient (Fig. 7a). Because of a varying degree of isolation from the mainstem channel and truncation of low waters due to high bed elevations, along-channel variations in LLW are considerably less regular for the floodplain stations than at channel stations, and floodplain MWL is also affected. The close agreement of HHW for the wetland and channel tide gauges suggests that the vertical reference corrections made to the wetland stations (see ESM-2) were reasonable. That is, we expect the smallest water-level gradients between the wetland and channel stations at HHW, when the water is deepest. Larger lateral gradients develop as water levels fall (and wetland low water may be delayed), because of the hindered drainage at wetland stations. Interestingly, the range (HHW-LLW) is larger at two wetland stations (Coal Creek Riparian and Westport Slough) than the trend established by the channel stations. This is a common phenomenon in the LCRE for gauges in peripheral areas (e.g., Youngs and Baker Bay) without strong fluvial flow but with adequate water depth; friction is reduced and some degree of resonance occurs (Jay et al. 1990).

The variability of floodplain water levels can be described in terms of deviations (Fig. 7b) or alternatively in terms of extremes (Fig. 7c). Irregularities induced by topography are evident, e.g., the reduced variability of LLW below $\mathrm{rkm}-60$ due to truncated low waters. However, the dominant factor is that the LLW, MWL, and HHW distributions are distinct in the estuary, but develop an overlap in the lower tidal river that becomes almost total above rkm180 (Fig. 7b, c). This overlap of distributions results from the fact that, in the more landward parts of the system, the seasonal cycle of river stage is much larger than the tidal range. 

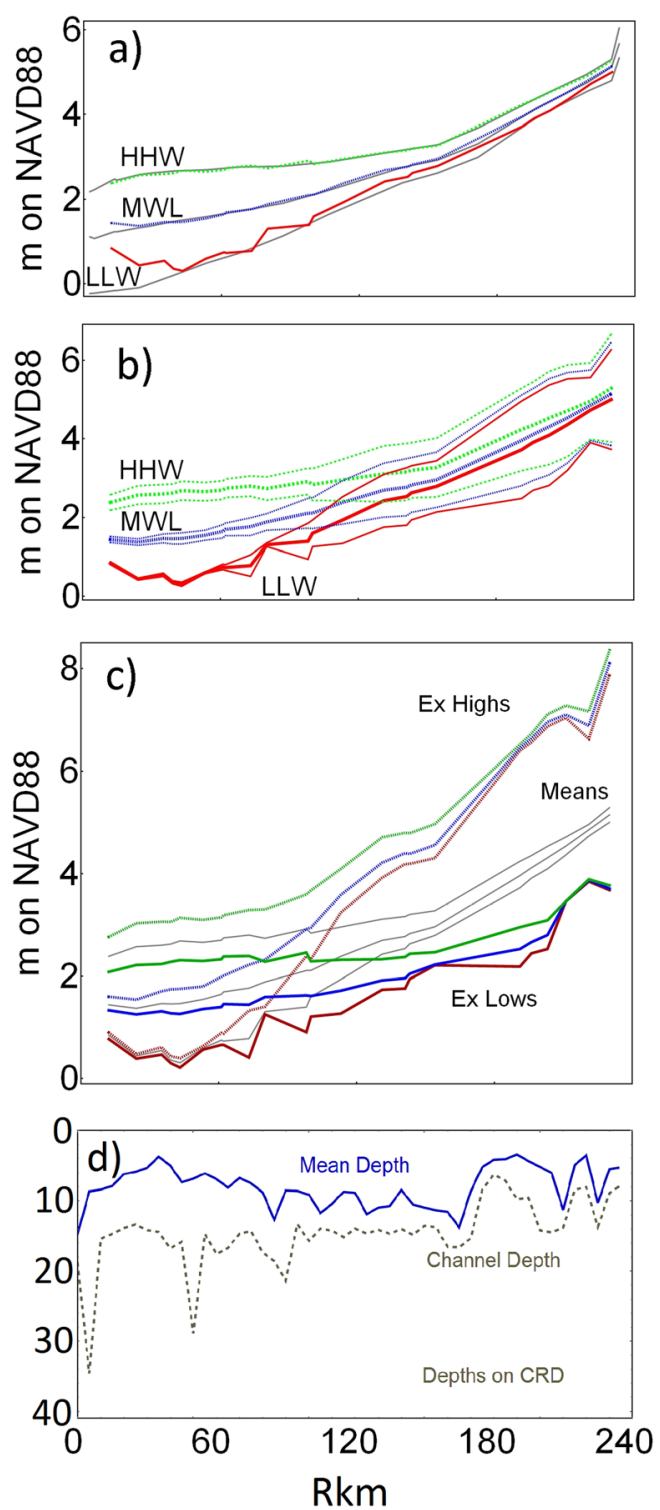

Fig. 7 a Means of LLW, MWL, and HHW on NAVD88 from 1991-2011 hindcast for channel stations (gray) and floodplain stations (colored); b means of LLW, MWL, and HHW and \pm 1 standard deviation from each of these means for floodplain stations; $\mathbf{c}$ for floodplain stations, means of LLW, MWL, and HHW (gray) and the lowest and highest $10 \%$ of LLW, MWL, and HHW; and d mean depth (laterally averaged) and thalweg or channel depth

\section{LLW, MWL, and HHW Distributions: Channel Stations}

We summarized 1991-2011 hindcast inundations at channel stations, as cumulative curves and percent occurrence to provide more insight into vegetation analysis and the physical mechanisms causing the distributions (Fig. 8). Factors affecting inundation in the estuary and tidal river are different, as described in the following paragraphs.

The distributions of LLW, MWL, and HHW at estuarine channel stations (e.g., Tongue Pt in Fig. 8) are compact, especially for MWL, and quite distinct from one another. The large
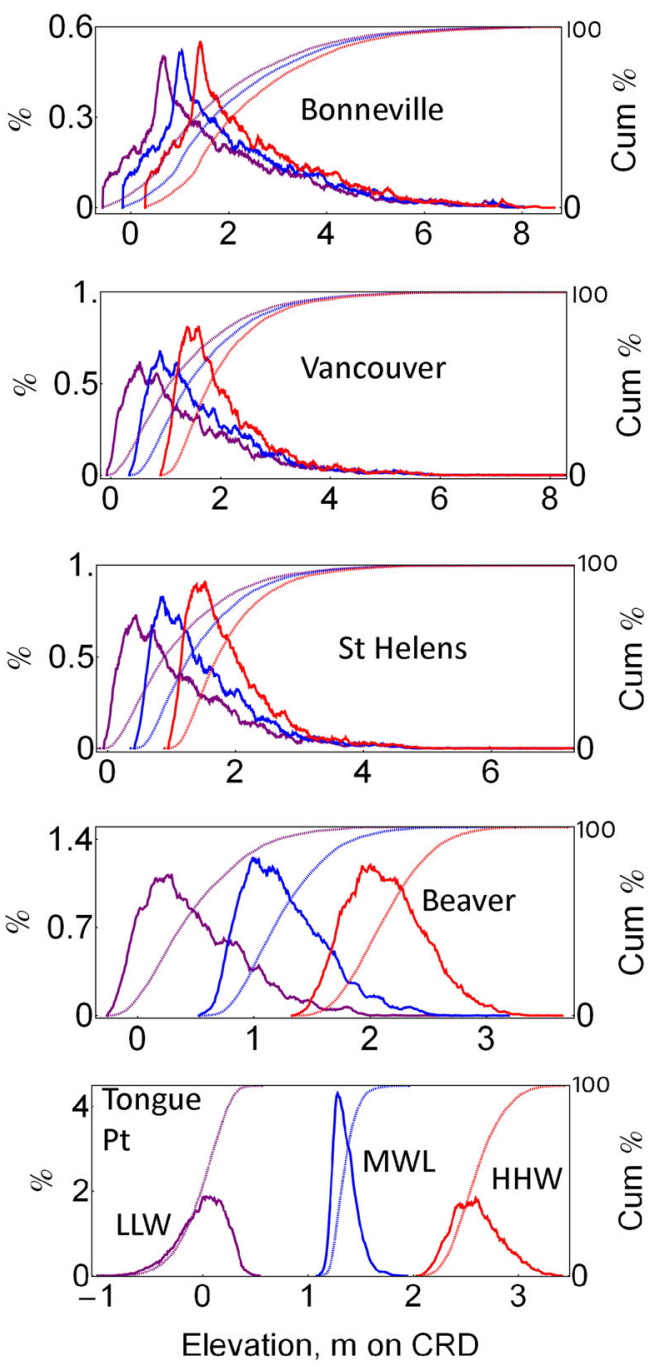

Fig. 8 The 1991-2001 hindcast inundation for five channel stations summarized as percent occurrence and cumulative percent occurrence of LLW, MWL, and HHW, all plotted relative to CRD. See Table 1 for rkm locations

tidal range at Tongue $\mathrm{Pt}$ is evident in the distance between the LLW and HHW peaks. The compact distributions at Tongue Pt reflect domination of water-level variations by a relatively predictable tide of moderate range, slightly perturbed by seasonal river flow fluctuations and by storm surges. LLW shows a skew toward low values (tail to the left), while MWL and HHW show a skew toward high values. These skewness patterns reflect in part extremes caused by coastal processes and storms, but are mostly determined by the interaction of the $\mathrm{D}_{1}$ and $\mathrm{D}_{2}$ tides. Tides of small to moderate range are common and have less diurnal inequality than very large tides, effectively placing a maximum on LLW and a minimum on HHW. On tides of large range, LLW follows HHW, and the following tides are less extreme. Thus, the extremes of HHW are positive deviations from the mean (of HHW) and the extremes of LLW are negative deviations. The shapes of the 
cumulative percent occurrence curves reflect integration of the percent occurrence.

There is a gradual change in the upriver direction in the form of the water-surface elevation distributions that reflects tidal-fluvial interactions. The distributions for the four more landward channel stations (Beaver to Bonneville) all differ from estuarine stations like Tongue Pt in four respects (Fig. 8):

(a) The individual distributions of LLW, MWL, and HHW are broader because of the influence of river flow variability, with the breadth increasing upriver.

(b) In the tidal river, there is a very long tail to the right (toward high values) for LLW, MWL, and HHW distributions that makes the extreme highs much higher than the medians for each distribution. This skew reflects the flow variability; the median flow $\left(5900 \mathrm{~m}^{3} \mathrm{~s}^{-1}\right)$ at Beaver is less than the average flow $\left(6570 \mathrm{~m}^{3} \mathrm{~s}^{-1}\right)$. Also, flow regulation prevents flows below $\sim 1800 \mathrm{~m}^{3} \mathrm{~s}^{-1}$ (30\% of the median), but high water levels are caused by occasional very high flows, up to $24,000 \mathrm{~m}^{3} \mathrm{~s}^{-1}$ ( $>400 \%$ of the median).

(c) The distances between the peaks of the three distributions are reduced, reflecting the reduced tidal range relative to the estuary. At Bonneville, the differences between the peaks reflect power-peaking more than tides.

(d) From St Helens landward, HHW is the narrowest peak. This occurs because the tidal range is much smaller for high flows so that the highest values of LLW and MWL during high flows are essentially the same as the lowest. In contrast, at low flows, the lowest value of HHW is considerably above those of LLW and MWL

As a result of these interacting factors, the distributions of LLW, MWL, and HHW increasingly overlap at more landward stations, such that their peaks are very close together in elevation at Bonneville.

\section{LLW, MWL, and HHW Distributions: Floodplain Stations}

The floodplain stations (Fig. 9) exhibit a transformation from the estuary (Chinook River Marsh) to near Bonneville Dam (Hardy Creek Marsh) similar to that for the channel stations, but modified by a variable degree of truncation of LLW and corresponding adjustments of MWL - as noted, truncation of LLW raises MWL. The distributions at Chinook Marsh and other estuarine stations are compact (like Tongue Point in Fig. 8), but the truncation of low waters causes very narrow LLW distributions (with skewness dictated by purely local factors) and increases the height of the peak of the LLW distribution. The shape and skewness of the HHW distribution, like that at channel stations, is dictated by interactions of the $\mathrm{D}_{1}$ and $\mathrm{D}_{2}$ tides and storm surges (see Part I). The three distributions at
Chinook River and Clatskanie River Marsh are largely distinct, but the degree of overlap increases sharply at Goat Island Marsh and Sauvie Cove. McGuire Island is unusual in that LLW is not truncated (because of the low elevation of this pressure gauge), whereas all other floodplain stations from Sauvie Cove landward have periods that are essentially non-tidal (especially Hardy Creek, which is intermittently isolated from the river during low-flow periods), such that the extreme low values of all three datums coincide. While HHW is the narrowest distribution at the more landward stations (as for the channel stations), it does not necessarily have the highest peak (in terms of percent occurrence) - LLW usually has a narrower, more peaked distribution due to the truncation of lower waters caused by the higher elevation of wetland channels compared to the channel stations.

\section{Vegetation and Sum Exceedance Value Analyses}

The average elevation of marshes is lower than that of shrubdominated wetlands, which in turn are lower than forested wetlands. Thus, each community has a distinctive hydrologic regime, with higher SEVs present in lower-elevation wetlands (Fig. 10). Average- and high-flow years also separate by SEV in the tidal river (Fig. 10). SEV increases sharply upriver (Fig. 11a), as do the percent fluvial and power-peaking components of the variance (Part I) and the fluvial influence on water levels in general (Figs. 4, 5, 7, 8, and 9). This landward increase in SEVs is expected because the seasonal cycle in river stage is much larger than the tidal range (Figs. 7, 8, and 9). During the 2007-2012 period, mean SEVs at emergent marshes ranged from $280 \mathrm{~m} /$ growing season in the estuary (rkm-0 to 39), to $3122 \mathrm{~m} /$ growing season in the upper tidal river (rkm-196 to 229; Fig. 11a). It is also apparent that total percent cover is higher in the estuary than in the tidal river, while average plant species richness peaks in the upper estuary (Fig. 11b). Of the 47 emergent marshes on the mainstem river that we analyzed, the minimum average absolute percent cover was $31 \%$ and the maximum was $138 \%$; the minimum plant species richness was 10 species and the maximum was 41 (cover values are not relative but absolute and therefore can exceed $100 \%$ where there is more than one vertical layer in the plant community.) A one-way ANOVA of average absolute percent vegetation cover by vegetation zone was significant ( $p=0.000$; adjusted $R^{2}=56.2 \%$ ). Tukey's all possible pair-wise comparisons of average absolute percent cover by vegetation zone showed significant differences between river reaches; the two estuary reaches were both significantly different from all three tidal river reaches. A one-way ANOVA of species richness also was significant $(p=0.001$; adjusted $R^{2}=28.3 \%$ ), and Tukey's all possible pair-wise comparisons of species richness for each reach showed the upper estuary 

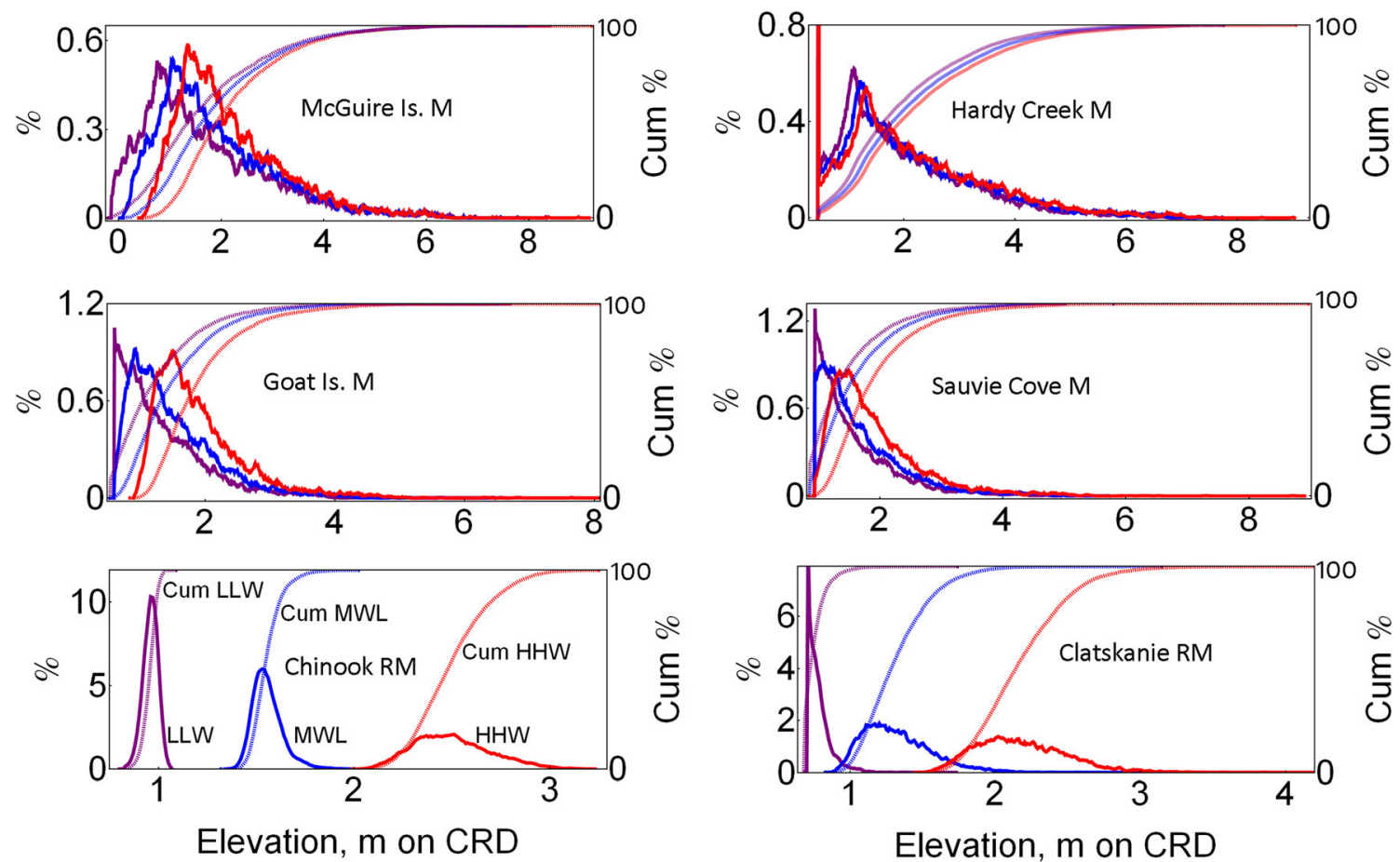

Fig. 9 Hindcast 1991-2011 inundation for floodplain stations, summarized as \% occurrence and cumulative \% occurrence of LLW, MWL, and HHW, all plotted relative to CRD. See Table 2 for rkm locations. $M$ marsh, $R M$ river marsh

zone significantly different from all the others except the Lower Tidal River.

Differences in the hydrologic regimes of vegetation zones are indicated by distinctive SEV patterns (Fig. 11a). A oneway ANOVA (ignoring water year) of $\log _{10} \mathrm{SEV}$ for each reach was significant (ANOVA; $p=0.000$; adjusted $R^{2}=65.8 \%$ ). Tukey's all possible pair-wise comparisons of $\log _{10} \mathrm{SEV}$ showed significant differences between river zones: the upper tidal river is significantly different from the lower tidal river and estuarine vegetation zones; the middle tidal river is significantly different from the estuarine reaches; and the lower tidal river is significantly different from the upper tidal river and the lower estuary and energy minimum. The linear regression of SEV on elevation shows little relationship when the entire LCRE is included $\left(R^{2}=0.19\right)$, but strong relationships for the three zones where data (the number of
Fig. 10 Sum exceedance values (SEVs) for 54 floodplain stations as a function of along-channel position and wetland elevation (Z), for average and high-flow years, and sorted by vegetation type. No complete records were available for low-flow years

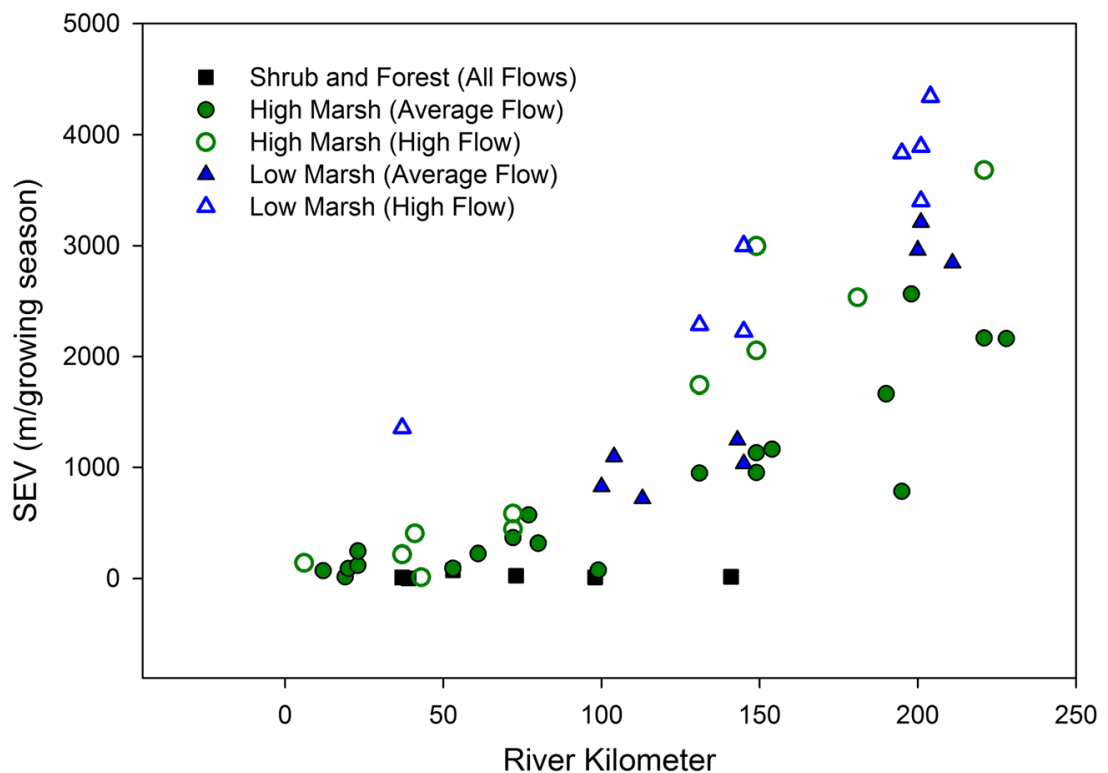


Fig. 11 a Mean sum exceedance values (SEVs) by vegetation zone for 54 tidal wetland records; vertical lines are $95 \%$ confidence intervals on reach means; all records for 2007-2012 are included, regardless of flows; and b average absolute vegetation cover and average plant species richness for sites in the five vegetation zones, with $95 \%$ confidence limits on both
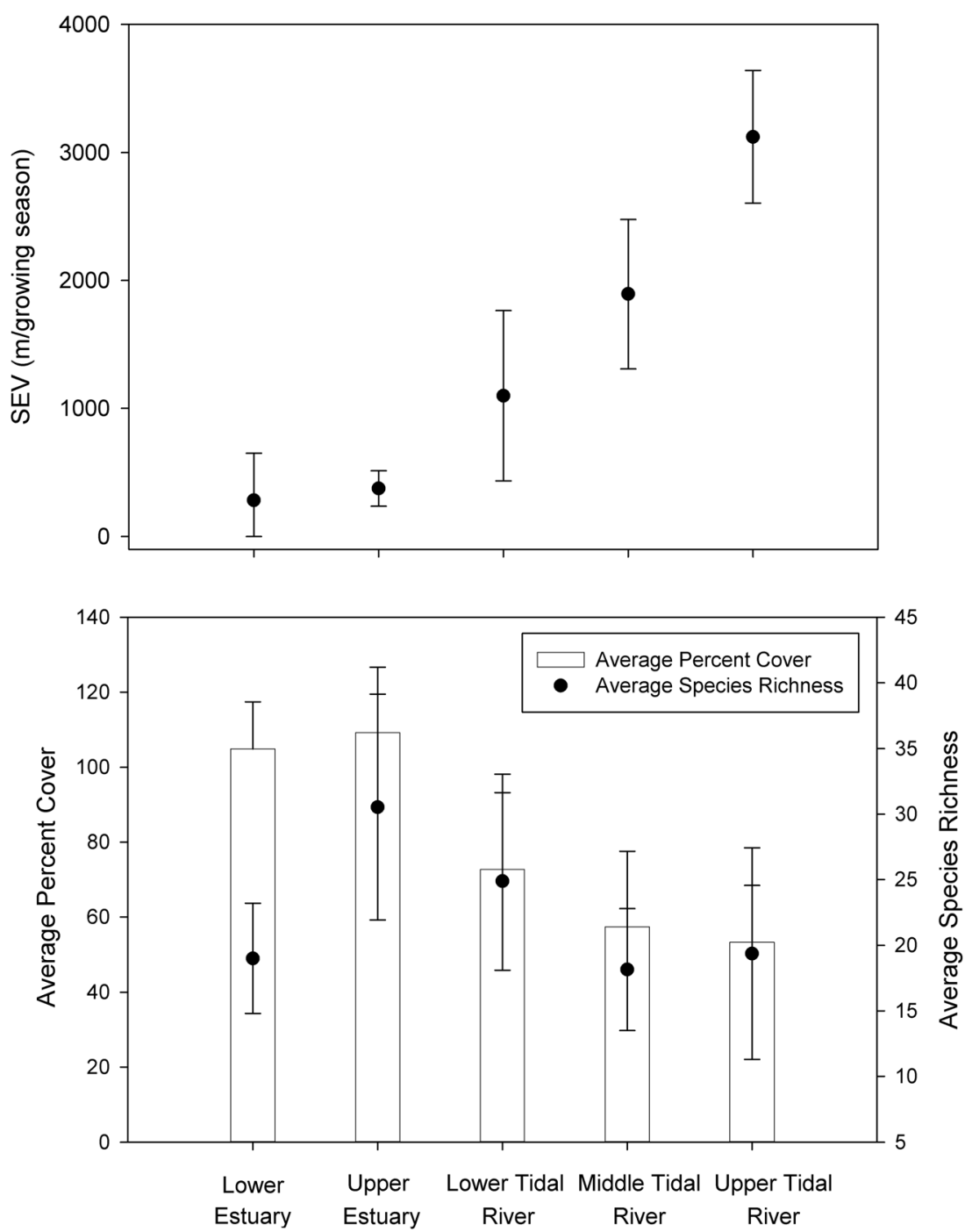

wetland sites) are sufficient: $\mathrm{rkm} 0-87, R^{2}=0.82$; rkm 88 $136, R^{2}=0.86$; rkm 137-190, $R^{2}=0.37(n=4)$; rkm 191$235, R^{2}=0.86$.

The effect of water year was not consistent across reaches. It is evident, however, that interannual differences in the SEV increase upriver along with the relative influence of river flow (Fig. 12). Thus, SEVs are a strong function of position, and the vegetation zones have different SEV characteristics, even though along-channel location is not directly related to wetland elevation on CRD. Before about 1970, upriver SEVs would have been even higher, because the spring freshets were less heavily regulated to reduce their volume and peak flow. Since about 1970 , there has been a strong shift in flows to the winter season, due primarily to flow regulation, but also to some extent to an increase in the incidence of winter floods in the Interior Subbasin (Jay and Naik 2011).

SEV estimates are available from 54, 1-year wetland pressure gauge records collected during the 2007-2012 period, but even this extensive compilation does not cover the parameter space defined by along-channel location, elevation and river flow. We have also, therefore, compiled potential SEV (pSEV) from the 1991-2012 channel tide gauge records to provide insight into SEV dynamics. These $\mathrm{pSEV}$ results can be used to summarize the spatial distribution of SEV as a function of river kilometer over a wide range of flow years (very dry to very wet) and for a range of hypothetical watersurface elevations from -0.5 to $7.5 \mathrm{~m} \mathrm{CRD}$, much broader than the actual range of wetland elevations (Figs. 12 and 13). For reference, the average of river flow at Beaver for 1971-2012 during the SEV season (22 April to 12 October) was $6770 \mathrm{~m}^{3} \mathrm{~s}^{-1}$, with a range from $3960(2001)$ to 10 , $200 \mathrm{~m}^{3} \mathrm{~s}^{-1}(2011)$ and quartile values of 5.51, 6.57 and $8.05 \times 10^{3} \mathrm{~m}^{3} \mathrm{~s}^{-1}$. Thus, 2011 and 2012 are well above the $75 \%$ percentile, 2008 is just under the $75 \%$ percentile, 2009 is close to the median, 2003 is close to the 25 th percentile, and 2001 is the lowest-flow year since 1878 . Obviously, the highest pSEVs occur for the lowest wetland elevations, but 

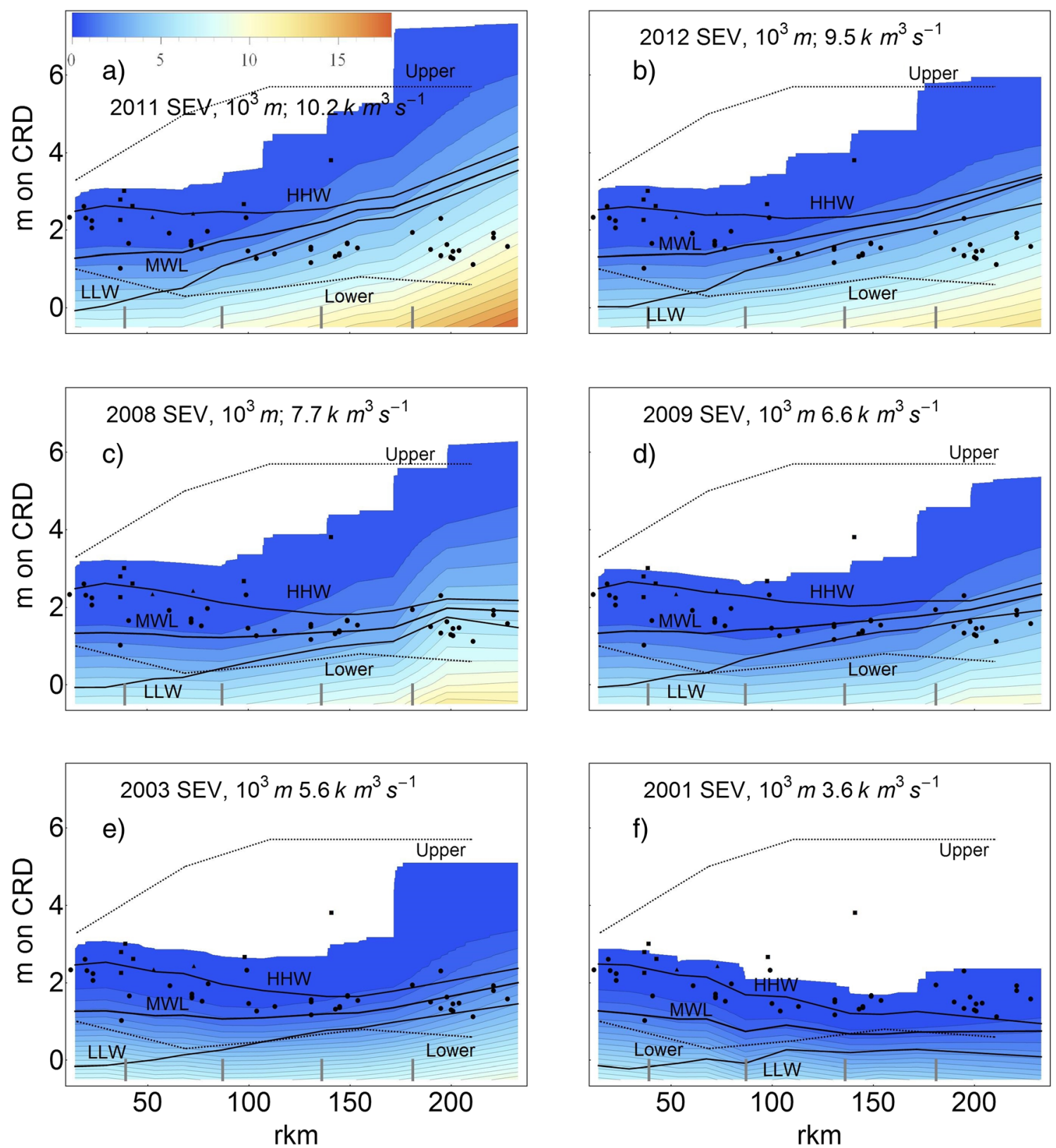

Fig. 12 Potential SEV (pSEV) (in $10^{3} \mathrm{~m}$ ) by along-channel position and wetland elevation for a series of years from a very wet (2011), to f extremely dry (2001); see text for details. The dotted lines indicate the upper and lower elevations of floodplain wetlands by reach. Flow levels

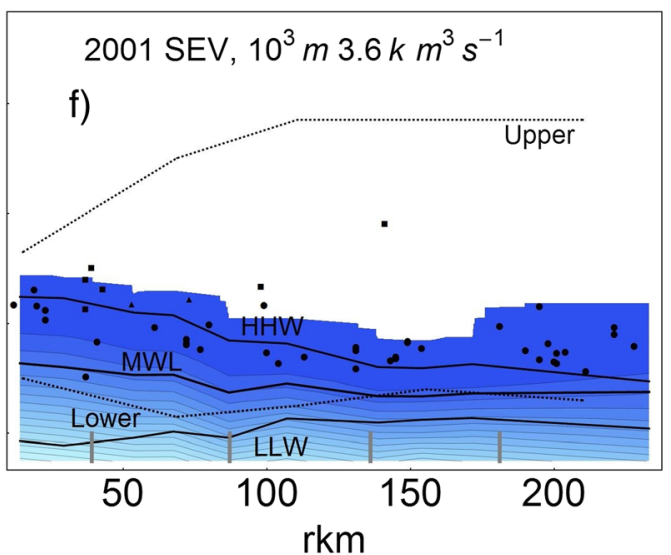

and means of LLW, MWL, and HHW are indicated by station and year; these values are compiled, like pSEV, from 4/22 to $10 / 12$ each year. The dots indicate the mean elevations of wetland sites, the gray vertical bars at the bottom indicate the approximate boundaries of vegetation zones

inter-annual variations are large. In 2001, pSEVs were considerably higher in the estuary than in the tidal river, but along-channel variations were weak relative to higher-flow years. The pattern of a local maximum in pSEV at or near the mouth continues for flows up to about the 75th percentile (2008).

Figure 13a, $\mathrm{b}$ show LLW, MWL, and HHW during the growing season, the fitted marsh elevation curve (all relative to CRD), and pSEV statistics (mean, standard deviation, and extremes) for the elevation of the fitted marsh

surface. The values of LLW, MWL, and HHW during the SEV season were somewhat elevated at upriver stations relative to annual averages (because the spring freshet occurs during the growing season), but lower than annual averages close to the ocean (because of upwelling during spring and summer). The pSEV summary in Fig. 13b and the time-series view of pSEV on the marsh surface (Fig. 13c, d) emphasize the inter-annual variability of pSEV. In the extreme low-flow year of 2001, marshsurface pSEV was relatively uniform and $\leq 300 \mathrm{~m}$ 
Fig. 13 a Average values of LLW, MWL, and HHW during the SEV growing season for 1991-2012 as a function of rkm, along with the marsh mean elevations and a 5 th-order polynomial trend fitted to these elevations $\left(R^{2}=0.669\right)$. The most extreme (low) marsh elevation was omitted from the fit, and the dots on the marsh fitted curve are the elevations at the long-term stations. b The fitted marsh elevation curve from a along with mean and extreme pSEVs and pSEV standard deviation as a function of rkm. $\mathbf{c}$ and $\mathbf{d}$ 1991-2012 pSEV histories for selected long-term stations seaward (c) and landward (respectively) (d) of the boundary between the estuary and the tidal river. Note that Warrendale (rkm-229) data from the $1980 \mathrm{~s}$ were used in estimating growing season MWL and HHW. It was not used for LLW because of an absence of low-flow years during the period or record for that station
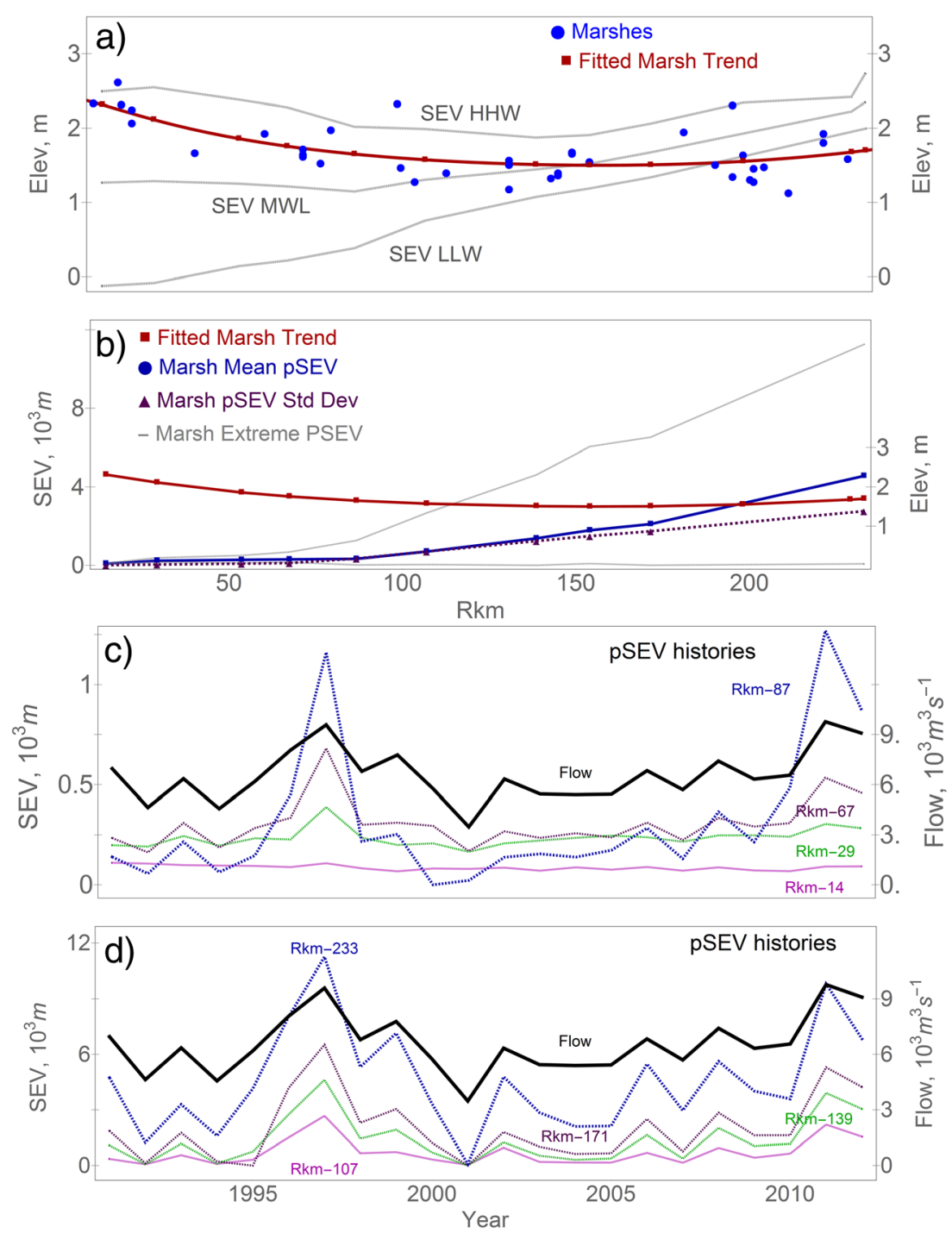

(Fig. 13c, d). Also, pSEV was uniformly low (except at rkm-233) from 1991 to 1994 and 2000 to 2007 but quite high from 1995 to 1999 and after 2010, reaching values in the range of 3600 to $6000 \mathrm{~m}$ at rkm-171 in the highest flow years. This inter-annual variability is less than it was under less-regulated flow conditions before 1970, but still presumably plays a role in regulating plant species distributions.

A comparison of fSEV and pSEV is provided in ESM-9.

\section{Discussion}

These results provide the basis for associating water-level properties with vegetation, evaluating the congruence of boundaries defining vegetation and hydrology, and proposing an integrated system classification based on water level properties and system geometry.

\section{Water-Level Response to External Forcing}

As described in Part I, the primary external forcing factors acting on the LCRE water-level regime are ocean tides, river flow, coastal and atmospheric processes (especially upwelling, downwelling, and pressure fluctuations), and powerpeaking. From a system perspective, the frictional interaction of tides and flow is the most important factor governing tidalfluvial water levels. Due to increased friction during periods of larger tides, LLW, MWL, and HHW all vary with tidal range as well as flow. The strongest neap-spring perturbations are of HHW and MWL, but LLW exhibits a very interesting effect, not shown by either MWL or HHW: increasing tidal range decreases LLW below Beaver but increases it above Beaver, for all flow conditions and values of Hammond tidal range. HHW and MWL increase with increasing tidal ranges at all stations for all flow levels, but the increase is strongest upriver from Beaver at low flows, because the increased 
elevation of LLW on spring tides raises the entire water-level profile. This we regard as a defining characteristic of a tidal river, and therefore, Beaver is effectively the boundary between the estuary and the tidal river.

This neap-spring reversal of low waters is seen in many tidal rivers in addition to the Columbia [e.g., the St. Lawrence (Matte et al. 2014), the Yangtze (Guo et al. 2015), the Amazon (Gallo and Vinzon 2005)]. It occurs because the nonlinear tidal monthly fluctuations grow upriver while the tide decreases. At some point, the amplitude of the tidal monthly oscillation is larger than the neap-spring difference in tidal amplitude, leading to LLWs that are lower on spring than neap tides. At least in the LCRE, the location of this tidal monthly reversal of low waters is not a function of flow, so it is seasonally stable. Analysis of a data set from the 1940s (not shown here) shows that this boundary has shifted little if any, despite $>4 \mathrm{~m}$ of channel deepening.

Tidal range is maximal in the estuarine energy minimum zone and decreases monotonically landward (despite a convergent geometry) due to the frictional effects of strong river flow, as expected in a tidal river (Giese and Jay 1989; Jay et al. 1990; and Godin 1999). Tides in the Upper Tidal River and Cascade zones are small, even during periods of low river flow. Thus, variations in Hammond forcing tidal range have almost no effect on the water-level range at Bonneville. The reason is simple - most of the nominal range at Bonneville (HHW-LLW) is due to power-peaking, and very little of it is due to actual tides, especially during high-flow periods. However, the power-peaking wave decreases rapidly as it propagates seaward. It is small below Longview, but detectable as far downriver as Wauna.

As expected, coastal downwelling raises estuarine water levels, but with some variability between stations, probably because of the correlation of local wind stresses with upwelling and downwelling, and the variable exposure of the gauges to local wind setup. The response to coastal winds decreases in the upper estuary. Further landward in the tidal river, downwelling coincides with lower, not higher, water levels. The apparent response to CUI in the western Columbia River Gorge reflects a correlation between CUI (calculated from wind gradients in coastal waters) and local winds - gorge outflow is often very strong when low pressure prevails offshore (Kukulka and Jay 2003a, b). The separate impacts of local winds were not tested here.

Along-channel differences in the inundation distribution functions (e.g., Figs. 8 and 9) for LLW, MWL, and HHW at channel stations reflect along-channel variations in forcing mechanisms. Inundation distributions are distinct and compact in the estuary, with MWL having the smallest variability (and thus, the highest percent occurrence peak). These narrow distributions reflect the dominance of tidal processes with limited variability, modestly perturbed by river flow and coastal processes. Stations more landward show increasingly broad and overlapping percent occurrence distributions, due to the increasing seasonal variations in the ratio of river stage to tidal range. Floodplain station inundation differs from that at channel stations mainly due to the truncation of low waters. During very low flows, some floodplain stations landward of about $\mathrm{rkm}-150$ are essentially isolated from the influence of river flow even at HHW. These differences in inundation are reflected in the SEV metric and wetland vegetation.

On the whole, the regression models present a coherent picture of system processes. However, irregularities in modeled water levels exist and are most prominent at very low and very high flows. These arise from several causes. First, there is necessarily a limited dynamic range of flows for the stations with short records, especially those for 1981 that are only $\sim 1 / 2$ year in length. Second, error bars are much broader for stations with short records. There are also genuine cross-channel differences in the broad lower estuary, especially between Knappton at rkm-24 and Tongue Pt, rkm-29. Tongue $\mathrm{Pt}$ is in an area of strong currents along the navigation (south) channel where channel development has focused river flow, whereas Knappton is on the north side of the estuary, where navigation structures (pile dikes and artificial islands) limit river through-flow. Tidal ranges are systematically larger in peripheral areas away from strong currents and friction (Giese and Jay 1989). They are smaller at Hammond (rkm14.5) than at nearby Ft Stevens (rkm-13.2) for reasons that are unclear. There are also irregularities in the along-channel profile that may be related to inter-agency differences in interpretation of CRD. Finally, there are likely decadal differences between the pre and post-1990 data. Tidal ranges have increased over time while MWL has dropped at upriver stations (Jay et al. 2011), so the diverse time periods of data collection at the various stations affect the modeled elevations. Thus, the constant $a_{0}$ decreased by $0.14 \mathrm{~m}$ for MWL at Bonneville between the 1980 s and post-1990 data (with $95 \%$ confidence limits of $<0.04 \mathrm{~m}$ in both cases).

\section{Relationship of Vegetation to Water Levels}

Large-scale hydrologic reconnection of river floodplains and coastal ecosystems is underway (Opperman et al. 2009; NMFS 2008; Diefenderfer et al. 2016). Thus, it is clearly important to establish methods for predicting wetland community development based on hydrologic characteristics of the system. As demonstrated in Part I, the controlling factors on the hydrologic template for wetland vegetation are complex. In Part II, we have calculated water-level statistics and indices to allow us to relate these complex external factors to wetland ecosystems and to evaluate spatial and temporal trends. We have found that water-level statistics for channel stations, for which relatively long records are available, can be predictive of the SEV at floodplain stations where properties are more difficult to observe and for which fewer records are available. 
Moreover, the SEV, an index of hydrologic conditions during the growing season (modified from Gowing and Spoor 1998), can be used to predict wetland vegetation characteristics in the LCRE. Both along-channel variations and inter-annual fluctuations in inundation are quantified by SEV (Figs. 11, 12, and 13 ), and these are well represented by potential SEV or pSEV. Thus, the calculation of pSEV, based on water levels at channel stations, permits us to evaluate or predict spatial and interannual variability in wetlands or restored areas, reducing the need to collect intensive or long-term site-specific field data.

The relationships between the elevation of marshes and the 20-year mean LLW, MWL, and HHW datums calculated from the channel stations change with along-channel river position, i.e., marshes are closer to mean HHW near the ocean entrance and drop monotonically with rkm until they are below LLW in the upper portion of the tidal river (Fig. 13). Moreover, LLW, MWL, and HHW during the SEV season have a narrower range upriver than in the estuary and that range is highly variable from year-to-year at upriver stations (Figs. 12 and 13a). Thus, in lowflow years like 2001, all sampled wetlands in the upper tidal river are above mean HHW while in high-flow years like 2011 all of these wetlands are below mean LLW (Fig. 12). At any point in the LCRE, forested and shrub wetlands would be above the line shown in Fig. 13a. However, we do not have the field data needed to specify the elevation of the ecotone between marsh- and shrub-dominated wetlands in the tidal river. Also, while the wetlands have not migrated in vertical elevation during the decade studied, inter-annual variability in species assemblage, biomass, and other metrics has been observed (Sagar et al. 2014). On a century time scale, changes in the hydrological cycle due to flow regulation by dams and reservoirs may also have eliminated some species and altered the distribution of others (Leyer 2005).

The SEV is related to other measures of inundation like percent occurrence (Fig. 9) and can be directly linked to vegetation because it integrates magnitude and duration of inundation over the growing season. SEV patterns are most consistent from year to year in the estuary, because tidal processes are less variable than river flow, yielding narrow and separated percent occurrence peaks for LLW, MWL, and HHW. Further upriver, the broad nature of the LLW and MWL peaks (Figs. 8 and 9) is reflected in high SEVs with strong interannual variability. While the SEV and $\mathrm{pSEV}$ provide a means of relating overall hydrologic patterns to wetland elevations and areal plant cover, they still do not allow us to evaluate the composition of plant associations within the LCRE. Nonetheless, SEV can provide guidance for system management by elucidating the spatial distribution of inundation conditions and time-space variations within that domain for comparison to the tolerance ranges of plant species and communities.

On the whole, variations in plant communities extending laterally from the mainstem channel in the estuary are strongly related to the intersection of mainstem river water-surface elevation and floodplain land-surface elevation (Fig. 10). Thus, the lower SEVs at higher elevations are conducive to the establishment of forested wetlands characterized by plant species that have less tolerance to inundation than those in emergent marshes (Fox et al. 1984). For a given along-channel position, SEV decreases with elevation, such that low-marsh $\mathrm{SEV}>$ high-marsh SEV $>$ shrub-wetland SEV $>$ forested-wetland SEV (Fig. 10). The upper limit of forested wetlands is difficult to determine, however Borde et al. (2011) estimates $\sim 5.5 \mathrm{~m}$ on CRD. Only upriver of rkm-170 is there any significant inundation above about $5 \mathrm{~m} \mathrm{CRD}$, but in some years, local inflow and subsurface processes may provide moisture in areas above this elevation.

Along the channel, we have shown that the general wetland vegetation characteristics of areal cover and species richness decrease in response to an increase in pSEV and to increased inter-annual pSEV variability (Fig. 11a, b). Other studies have shown that fewer plant species and different species assemblages are present in wetland communities at the landward end of the LCRE (Borde et al. 2012a, b; Christy and Putera 1993; Kunze 1994; Sagar et al. 2014). Likely, these are species that are more resilient to inter-annual and seasonal changes in hydrology. Similarly, low species richness occurs in the lower estuary where salinity limits the number of species (Odum 1988). In contrast, highest species richness is found in the upper estuary where the oligahaline marshes transition to tidal freshwater, similar to patterns observed by Sharpe and Baldwin (2009, 2013).

The potential effects of the large inter-annual variations in inundation (quantified by pSEV; Figs. 12 and 13) on wetland elevation ranges merit consideration. Mean marsh elevations are near growing-season HHW in the lower estuary, where inter-annual SEV variability is low and the tidal range is large. They decrease so that they are near growing-season MWL between about rkm 140 to 160, and are below growingseason LLW upriver of about rkm-190, where inter-annual SEV variability is high. While we cannot provide a definitive interpretation of this fact, the low elevation of upriver wetlands is consistent with the extreme variability of SEV in that environment. Upriver wetland plants are capable of enduring prolonged inundation in wet years, but presumably this also requires that they be located at an elevation that provides some inundation in all years; this can only be consistently found below the mean value of growing season LLW. The duration of the effects of extreme years like 2001 (dry) and 2011 (wet), and the cumulative effects of multiple consecutive dry or wet years, on LCRE wetland ecosystems are as yet unknown.

\section{System Zonation}

Regression model results, topography, salinity intrusion, the balance of tidal and fluvial forces, and analyses of vegetation 
at 47 emergent marshes near the mainstem Columbia River (Borde et al. 2012a, b) suggest a system zonation involving four zones and eight reaches, within which are nested five herbaceous tidal wetland vegetation zones (Fig. 1). To the extent possible, boundaries are associated with hydrodynamic processes and hard-rock features, though some of the latter are man-made. The system zones and reaches are as follows:

1. The Entrance zone, rkm-0 to 5, coincides with the Mouth of the Columbia River navigation project. It extends from the ocean to Jetty A and is dominated by waves and tidal processes. Prior to jetty construction 1883-1937, it was an open coastal environment. Mean river flow velocities are smaller here than in more landward reaches, but stratification caused by salinity intrusion creates a strong, complex and layered exchange flow. While this reach is clearly distinct in terms of physical processes, it has not played much of a role in this study, because no data on vegetated wetlands are available and water-level data have not been collected here in recent years. Absent vegetation data, this zone is included with nearby estuarine reaches in the most seaward vegetation zone, the Lower Estuary.

2. The Estuary zone, rkm-5 to 87 , consists of three reaches:

- The Lower Estuary reach, rkm-5 to 21, extends from the entrance to a natural lateral constriction, now the site of a bridge. It is affected primarily by tides and salinity intrusion, but wave action affects beaches and mid-estuary flats. Its landward boundary corresponds approximately to the upstream limit of salinity intrusion during typical spring high flows (Jay and Smith 1990). The estuarine turbidity maximum is often found here, trapped in deep holes in both the North and South Channels associated with the bridge constriction (Jay et al. 1990). There are large peripheral bays on the south and north sides. Currents from river flow are large relative to most estuaries, but smaller than in the tidal river (Giese and Jay 1989).

- The Energy Minimum reach, rkm-21 to 39 is located in the widest part of the estuary (Jay et al. 1990). There are large peripheral bays to the north (with significant freshwater inflow) and the south. The largest tidal ranges in the system are associated with tide wave reflection from Tongue $\mathrm{Pt}$ (rkm-29). Salinity intrusion occurs at the end of flood during periods of low to moderate flows (Chawla et al. 2008), although salinity and stratification are usually absent on greater ebbs. Sand is not easily transported through this relatively wide reach, because of low energy levels (Jay et al. 1990).

The Entrance zone and first two Estuary reaches make up the Lower Estuary brackish (0.5-18 ppt) vegetation zone (rkm-0 to 39; Zone 1). Here, tidal emergent wetlands have high vegetative cover with relatively low species richness. The landward boundary for oligohaline $(0.5-5 \mathrm{ppt})$ tidal wetland plant communities is variable due to seasonal and inter-annual differences in the landward limit of salinity intrusion ( between rkm 20 and 50) caused by flow variations (Chawla et al. 2008).

- The Upper Estuary reach, rkm-39 to 87 has a generally convergent cross-section and increasing fluvial influence, with maximum near-bed salinity intrusion that may reach to $\mathrm{rkm}-50$ during low-flow neap tides though near-surface salinity is absent (Jay and Smith 1990). River flow is strong enough that tides are considerably damped, despite the convergent geometry. The lower part of this reach encompasses a wide bay with numerous islands and subsidiary channels. There was no natural deep-water channel through much of this reach. Accordingly, sand transport through this zone occurs only during periods of elevated flow. There is a clear boundary at Beaver (rkm-87) based in geology and tidal processes. Here, confined by the eastern part of the coastal mountains, the river abuts a steep cliff to the north, with a broad area of mostly diked floodplain south of the channel. At this point, tidal properties change: seaward, LLW is lower on spring than on neap tides and landward, friction increases river surface slope on spring tides, causing spring LLW values to be elevated above those on neap tides; this feature defines the division between the estuary and tidal river. Also, tidal reversal of currents generally does not occur landward of Beaver, except during low-flow periods. Finally, at and below Beaver, tidal variance exceeds seasonal-fluvial variance. Landward of Beaver, seasonal-fluvial variance is larger (Part I).

The Upper Estuary vegetation zone (rkm-39 to 87; Zone 2) coincides with the system reach of the same name. Emergent wetlands in this zone are tidal freshwater and have high vegetative cover and high species richness. The invasive wetland plant, reed canarygrass (Phalaris arundinacea) increases in areal cover in this vegetation zone, and becomes more dominant in all zones more landward.

3. The Tidal River zone, $\mathrm{rkm}-87$ to 229 , extends from the constriction at Beaver to the seaward end of the landslide upon which Bonneville Dam is built (O'Connor 2004), $5 \mathrm{~km}$ below Bonneville Dam. It consists of three reaches:

- The Lower Tidal River reach, rkm-87 to 139 is confined by steep topography on both sides and has a floodplain of limited width, with the exception of tributary mouths. Unlike reaches landward and seaward, there is a single major channel in most 
locations. River flow effects increasingly dominate over tidal effects in this reach.

This reach coincides with the Lower Tidal River vegetation zone (Zone 3), which is characterized by emergent tidal wetlands with moderate vegetative cover and moderate species richness.

- The Middle Tidal River reach, rkm-139 to 196, encompasses the extensive historical floodplain at the confluence of the Columbia and Willamette Rivers and extends to the western edge of the Columbia River gorge. The seasonal excursion of river stage (MWL) is much larger in the landward part of the system than the tidal range, and tidal ranges vary seasonally by as much as an order of magnitude, due to damping of the tide by river flow. Seasonal-fluvial variance is much larger in this zone (Part I), and power-peaking variance is noticeable.

This reach coincides with the Middle Tidal River vegetation zone (Zone 4), which is characterized by emergent tidal wetlands with lower vegetative cover and relatively low species richness.

- The Upper Tidal River reach, rkm-196 to 229, has little floodplain and is confined by the cliffs of the Columbia River Gorge. It extends to the base of the Bonneville landslide. Tides are quite small, seasonal water-level fluctuations very large, and powerpeaking effects prominent.

The most landward vegetation zone, the Upper Tidal River (rkm-196 to 234; Zone 5), is also characterized by emergent tidal wetlands with low vegetative cover and relatively low species richness. While wetlands in this zone have many characteristics similar to the Middle Tidal River, the wetland vegetation is typically more variable between years in response to the more dramatic variation in hydrologic conditions near Bonneville Dam (Sagar et al. 2014).

4. The Cascade zone, rkm- 229 to 234 , comprises the final $4 \mathrm{~km}$ of the system below Bonneville Dam. This zone has a much steeper bed slope than the tidal river, due to the ca. 1450 landslide. Turbulence levels are, accordingly, very high. Seasonal MWL fluctuations related to river flow are even larger than in the tidal river; tides are minimal and smaller than power-peaking effects. No data on wetland vegetation are available, and though the opportunity for wetland development is limited by geologic and hydrologic conditions, it is included in the Upper Tidal River vegetation zone.

The above zonation, motivated by a study of vegetation, does not consider coastal waters. However, it is reasonable to extend the larger estuarine system offshore to include the tidal plume (boundaries defined by HornerDevine et al. 2009), because of its importance to juvenile salmon (e.g., Bottom et al. 2005). Then our zonation largely agrees with that of Day et al. (1989), who divide the larger estuarine system into a near-shore turbid zone, the estuary proper, and a tidal river zone. The only difference is that Day et al. use salinity intrusion length to divide the estuary and tidal river, a division that is unworkable in the LCRE and other large river estuaries where salinity intrusion is either highly variable or absent.

\section{Tidal Wetland Vegetation Zones and Other Systematic Approaches}

The boundaries of the system zonation are generally congruent with five potential herbaceous tidal wetland vegetation zones as discussed above (Fig. 1). However, the transitions between vegetation zones are less specific due to the noncontinuous positions and limited number of wetland study sites. We note that the system zones and reaches are defined in two-dimensional space, but the responses of plant species to the magnitude and timing of inundation varies with the year, with distance from the thalweg, and with vertical position. It may also respond over time-frames longer than 1 year. Thus, the vegetation zone boundaries must be considered somewhat uncertain. Additionally, it should be noted that the vegetation zones were developed with data from emergent marshes and do not necessarily represent the distribution of trees and shrub communities.

The decision not to restrict the Upper Estuary system zone to the salinity-intruded part of the system merits comment. Our landward limit at rkm-87 coincides with the location of a constriction that marks the usual (but not maximum) upstream limit of current reversal and also the location landward of which the lowest water levels occur on neap (not spring) tides. In contrast, Cowardin et al. (1979; FGDC 2013) defines estuaries as extending to the landward limit of salinity intrusion (the 0.5 PSU contour), a standard that is impractical in a tidal river, where salinity intrusion is extremely variable. On the other hand, the Coastal and Marine Ecological Classification Standard (FGDC 2012) uses the head of the tide. This definition is also unsatisfactory in large tidal rivers, e.g., $1000 \mathrm{~km}$ of tidal river in the Amazon (Gallo and Vinzon 2005). Clearly, a more nuanced approach is needed and we have attempted to provide one that is applicable to the LCRE study area and many other large tidal rivers, e.g., the Yangtze, which is tidal to $\sim \mathrm{rkm} 650$ (Guo et al. 2015).

Discriminating the spatial distribution of tidal wetland features including plant assemblages and channel morphology in the reach between rkm 87 and $\mathrm{rkm} 104$ is complicated, and the fact that our boundary at $\mathrm{rkm}-87$ is not congruent with prior classifications deserves explanation. A classification of natural areas in the lower Columbia River previously demarcated freshwater tidelands from the overflow plain at rkm 104 
(Christy and Putera 1993), and a 7-km-wide hydrogeomorphic reach boundary by Simenstad et al. (2011) extends from rkm 100 to rkm 107. Christy and Putera (1993) noted that the coastal wetland plant indicator species Carex lyngbyei (Callaway et al. 2012) is not present above Crims Island (rkm 89), and the furthest upriver that we have identified it is at Gull Island (also at rkm 89) (A. Borde, unpubl. data). It has been suggested that channel morphology is meandering below rkm 104 but linear and parallel to the mainstem river above that location (Christy and Putera 1993). However, it is evident from examination of both aerial imagery and a recent geomorphic classification (USGS 2012) that both meandering and linear channels are present between rkm 87 and rkm 104. In these $17 \mathrm{~km}$, linear channels are characteristic of the islands created by dredged material, and both linear and meandering channels are present on the floodplain lateral to the mainstem channel. Between rkm-87 and 104, inter-annual differences between the relative contributions of Coastal Subbasin discharge and Interior Basin discharge (see Fig. 1) to flow are noticeable in the magnitude and timing of high flow peaks, because this reach is immediately downriver of the most seaward major tributary (the Cowlitz). On balance, considering currently available information regarding the hydrologic regime, plant indicator species, bedrock geology and wetland channel morphology, we distinguish wetlands associated with the Upper Estuary from those associated with the Lower Tidal River at rkm 87.

This division of the system resulting from analyses of water levels and vegetation data has some similarities to the eight hydrogeomorphic reaches delineated by Simenstad et al. (2011), despite different selection criteria. For example, the upper boundaries of our Estuary (rkm-21), Lower Tidal River (rkm-139), and Middle Tidal River (rkm-196) roughly correspond to the upper boundaries of hydrogeomorphic reaches A, E, and G in Simenstad et al. (2011). Our use of water-level properties leads, however, to an important difference: water-level properties tend to change at constrictions caused by hard-rock shoreline features where tidal wave reflections occur and river flow velocity changes abruptly. In contrast, the tributaries frequently used to mark boundaries by Simenstad et al. (2011) generally occur between constrictions. Also, we distinguish additional seaward and landward system zones, the Entrance and the Cascade.

\section{Applications}

This study reveals the complex details of water-level processes in a single system under a management regime that emphasizes hydropower production and navigation. The Columbia Basin is also in a tectonically active region with generally steep coastal topography and recent glaciation. Given the physiographic and anthropogenic template of the river, it is worth considering the potential generality of our methods and findings, including natural conditions or other management strategies, and other tidal river systems.

\section{Applicability to Other River Systems}

The LLW, MWL, and HHW distribution functions and the regression models on which they are based provide a means to summarize and hindcast water levels over long time periods, with only modest computational requirements. These models can easily be applied to other systems, or to the LCRE under historical (pre-1900) conditions, when the river was steeper and tides smaller (Jay et al. 2011). Also, this approach might be useful in understanding wetland habitat in different tidal regimes (diurnal, semidiurnal, and mixed) and provides useful model calibration/validation tools for nonstationary tidal rivers. The usual approaches to validating tides in coastal models (e.g., Foreman et al. 1995) assume stationarity of processes and do not determine whether models respond appropriately to variations in river flow. Thus, they are not appropriate to most tidal rivers. The main restriction on this use is that the regression models require the barotropic water-level adjustment time to be short relative to the time scale of the changes in external forcing. Since the barotropic adjustment is a long wave moving more or less at the speed of the tide, this condition will not normally be limiting.

Because pSEV is integrative (over the growing season), it averages out many nonlinearities. Thus, pSEV distributions may be more similar between systems than other water-level properties, although calculations for other systems should use the local growing season, and this may have a different relationship to the hydrological cycle than is the case in the LCRE. The primary requirement for using SEV or pSEV for inter-annual or spatial comparisons is that the time period integrated must be the same for all locations and time periods. In terms of the tidal stations needed to map pSEV in a system, one criterion might be that $\mathrm{O}(10)$ are needed per tidal wavelength. In the LCRE the tidal wavelength varies with tidal species and river flow, but the system is about one wavelength long for both the diurnal and semidiurnal tides. Understanding SEV in relation to wetland vegetation requires a considerable larger number of wetland stations, the number depending perhaps on the number of vegetation zones.

Power-peaking is widespread in systems with hydroelectric dams, but its tidal-river impacts have not been broadly examined. The most obvious generalizations from this study are that: (a) power-peaking waves travel seaward as a pseudo-tide, and (b) that these waves will evince quasi-periodic behavior, with daily, weekly and seasonal variability being likely, in additional to interannual changes.

The rapid decrease in coastal influences on water-level processes relative to the tidal wavelength is also likely common. However, many tidal rivers are short relative to the tidal wavelength, due either to steep topography and strong friction (e.g., 
the Skokomish, a tributary to Puget Sound; Jay and Simenstad 1996) or weirs (as in the Hudson River (Georgas et al. 2013) and many European rivers). The former should exhibit similar along-channel development of the water-level regime, compressed into a shorter distance. The latter, because they typically have a strong reflected wave, may be fundamentally different in that there is often a prominent maximum in tidal range near the weir. Long, low-gradient systems, especially those with large tides like the Gironde, France (Castaing and Allen 1981), may also exhibit behaviors rather different from the LCRE, because along-channel modification of the tides is, over most of the length of the system, due to tidal wave distortion, not river flow. The dynamics of many tropical and semi-tropical rivers (even those with high flows) are also quite different due to the presence of multiple distributaries (Buschman et al. 2010; Sassi et al. 2011). Still, the methods used here could help to describe the properties of these systems and be used for comparative analysis of tidal river systems worldwide.

Finally, we suggest that our proposed estuary-tidal river boundary is likely to be widely applicable, because it is based on nonlinear dynamics that occur in all tidal rivers. If tidal intrusion is not truncated by a barrier, tidal monthly oscillations will typically grow landward to the point that they are large enough to cause the neap-spring reversal of the lowest low waters, which we regard as diagnostic of a tidal river.

\section{Utility of pSEV as a Planning Tool}

The present wetland elevation range is narrow relative to the potential changes in water levels related to climate change in the Columbia River basin and sea level rise. Despite minimal Pacific Northwest sea level rise since ca. 1980 (Bromirski et al. 2011) and dropping water levels in the tidal river (Jay et al. 2011), recent predictions suggest sea level rise on the Washington and Oregon coasts of $\sim 0$ to $0.5 \mathrm{~m}$ by 2050 and 0.1-1.4 m by 2100 (cf. Qian et al. 2009; National Research Council 2012). Combined with reduced sediment loads in recent decades due to flow regulation and diversion (Naik and Jay 2011) and extensive removal of sand (dredging and sand mining; Templeton and Jay 2013), sea level rise may cause substantial changes to LCRE habitats. Because it can be estimated for all wetland elevations and interpolated to any alongchannel position, pSEV could assist in evaluation of sea levelrelated changes and of impacts of restoration of presently diked tidelands. It could also be used as a predictive measure for any hypothetical flow cycle that would be produced by future flow regimes. This is computationally much more efficient than predicting inundation for lengthy periods by numerical modeling. We note, however, that pSEV is an approximation to wetland inundation. Because it does not take into account lateral gradients in elevation, and because alterations like dike removal will locally change the water-level regime, pSEV is a planning rather than design tool.
The effects of possible changes in water-level properties and vegetation patterns, whether related to restoration or climate change, have not been modeled for the LCRE floodplain. The mean elevation of most tidal emergent wetlands in all zones of the LCRE study area is 1-3 m CRD (Fig. 13a), and the cumulative percent occurrence curves in all but the most landward vegetation zone (zone 5) (Figs. 8 and 9) indicate that most inundation occurs between 0 and $3.5 \mathrm{~m} \mathrm{CRD}$. While no wetland data are known to have been collected for very low water years (e.g., 2001), high water years have been shown to lower both vegetative cover and productivity (Borde et al. 2012a, b). Analysis of the upper- and lower-elevation limits at which emergent herbaceous wetland plants are observed relative to inundation patterns (Fig. 12) shows that in the more tidally influenced regions of the river, the distribution of vegetation is limited at lower elevations. Wetlands dominated by woody plant species (trees and shrubs) tend to be located at higher elevations and sometimes further from the main channel than emergent marshes (Fox et al. 1984), because of the lesser inundation tolerance of these plant species. The wetlands distant from the thalweg have the potential to be more influenced by small-scale, local processes, e.g., inflow from peripheral streams and groundwater. Nonetheless, pSEV calculated from the channel station data is predictive of broad inundation patterns, even at the higher elevations.

Climate projections indicate that a warmer, future Columbia River Basin will have very different hydrologic patterns whether annual average precipitation increases slightly (as projected; Hamlet et al. 2013; Salathé et al. 2014) or decreases. While overall flood risk will increase, peak flows are shifting from spring into winter. The SEV measures used here do not contain any direct information regarding temperature changes, but increasing temperatures would lengthen the growing season, potentially shifting its onset to an earlier year-day and its end to a later one. The Columbia River reservoir system will have increasing difficulties in providing flows during the growing season and for migrating salmonids (Naik and Jay 2011; Hamlet et al. 2013). To the extent that projections of growing seasons, flows, and water levels are available, pSEV can be used for planning purposes, though water temperatures also need to be considered. In particular, pSEV could be used in evaluating the reservoir management scenarios that are being considered in ongoing Columbia River treaty negotiations between Canada and the USA (Bonneville Power Administration 2012).

\section{Conclusion}

Parts I and II of this paper have developed the basis for a new zonation of the lower Columbia River and estuary, through the analysis of data on mainstem channel and floodplain tidal wetland water levels and wetland vegetation. In so doing, we have demonstrated the integrated application of several 
analytical and modeling tools: in Part I, power spectra, continuous wavelet transforms, and harmonic analyses, and in Part II, regression models, statistical tests, and sum exceedance values (SEV). We have also developed and validated a new predictive tool, the potential SEV (pSEV), with potential utility for spatial planning of tidal wetland distributions under restoration and climate change scenarios. The new zonation, based on the bottom-up analysis of hydrologic and vegetation data from 19 mainstem channel stations and 23 tidal freshwater and brackish wetlands, should provide a useful template for spatial stratification of subareas in future wetland or hydrologic sampling designs in this region. We also hope that the multi-faceted analytical approach will likewise have utility for studies in other complex tidal freshwater river systems.

Acknowledgments This work was supported by the US Army Corps of Engineers Columbia River Fish Mitigation Program. Funding for floodplain water-level data collection by PNNL was also provided in part by the Bonneville Power Administration and Lower Columbia Estuary Partnership. Partial support for D. A. Jay was provided by the National Science Foundation, grant OCE-0929055. We thank V. Cullinan, R. Kaufmann, K. Leffler, C. McNeil, and S. Zimmerman for technical assistance.

\section{References}

Bakun, A. 1973. Coastal upwelling indices, west coast of North America, 1946-71. U.S. Department of Commerce, NOAA Technical Report NMFS-SSRF-671, 103 p.

Baldwin, A.H., M.S. Egnotovich, and E. Clarke. 2001. Hydrologic change and vegetation of tidal freshwater marshes: field, greenhouse, and seed-bank experiments. Wetlands 21: 519-531.

Bonneville Power Administration. 2012. Assessing the Canadian Hydro Operation Post 2024 in the Absence of the Treaty, Portland, 94 pp.

Borde A.B., S.A. Zimmerman, R.M. Kaufmann, H.L. Diefenderfer, N.K. Sather, and R.M. Thom. 2011. Lower Columbia River and Estuary Restoration Reference Site Study: 2010 Final Report and Site Summaries. PNWD-4262, prepared for the Lower Columbia River Estuary Partnership and the Bonneville Power Administration by Pacific Northwest National Laboratory, Marine Sciences Laboratory, Sequim, WA.

Borde A.B., V.I. Cullinan, H.L. Diefenderfer, R.M. Thom, R.M. Kaufmann, J. Sagar, and C. Corbett. 2012a. Lower Columbia River and Estuary Ecosystem Restoration Program Reference Site Study: 2011 Restoration Analysis. PNNL-21433, prepared for the Lower Columbia River Estuary Partnership by Pacific Northwest National Laboratory, Marine Sciences Laboratory, Sequim, WA. Available URL: http://www.pnnl.gov/main/publications/external/ technical_reports/PNNL-21433.pdf.

Borde A.B., R.M. Kaufmann, V.I. Cullinan, S.A. Zimmerman, and C.L. Wright. 2012b. Lower Columbia River and Estuary Habitat Monitoring 2011 Annual Report. PNNL-21128, prepared for the Lower Columbia River Estuary Partnership by Pacific Northwest National Laboratory, Marine Sciences Laboratory, Sequim, WA.

Bottom, D. L., C. A. Simenstad, J. Burke, A. M. Baptista, D. A. Jay, K. K. Jones, E. Casillas, and M. H. Schiewe. 2005. Salmon at river's end: The role of the estuary in the decline and recovery of Columbia River salmon. U.S. Dept. of Commerce, NOAA Tech. Memo., NMFS-NWFSC-68, 246 pp.
Bromirski, P.D., A.J. Miller, R.E. Flick, and G. Auad. 2011. Dynamical suppression of sea level rise along the Pacific coast of North America: indications for imminent acceleration. Journal of Geophysical Research 116, C07005. doi:10.1029/2010JC006759.

Bunn, S., and A. Arthington. 2002. Basic principles and ecological consequences of altered flow regimes for aquatic biodiversity. Environmental Management 30: 492-507.

Buschman, F.A., A.J.F. Hoitink, M. van der Vegt, and P. Hoekstra. 2010. Subtidal flow division at a shallow tidal junction. Water Resources Research 46, W12515. doi:10.1029/2010WR009266.

Callaway, J.C., A.B. Borde, H.L. Diefenderfer, V.T. Parker, J.M. Rybczyk, and R.M. Thom. 2012. Pacific Coast tidal wetlands. In Wetland habitats of North America: ecology and conservation concerns, ed. D.P. Batzer and A.H. Baldwin, 103-116. Berkeley: University of California Press.

Castaing, P., and G.P. Allen. 1981. Mechanisms controlling seaward escape of suspended sediment from the Gironde: a macrotidal estuary in France. Marine Geology 40: 101-118.

Chawla, A., D.A. Jay, A.M. Baptista, M. Wilkin, and C. Seaton. 2008. Seasonal variability and estuary-shelf interactions in circulation dynamics of a river-dominated estuary. Estuaries and Coasts 31: 269288.

Christy, J.A., and J.A. Putera. 1993. Lower Columbia River natural area inventory: 1992. Portland: Oregon Natural Heritage Program.

Cornu, C., and S. Sadro. 2002. Physical and functional responses to experimental marsh surface elevation manipulation in Coos Bay's South Slough. Restoration Ecology 10: 474-486.

Cowardin, L.M., V. Carter, F.C. Golet, and E.T. LaRoe. 1979. Classification of Wetlands and Deepwater Habitats of the United States. U.S. Department of the Interior Fish and Wildlife Service, FWS/OBS-79/31. Washington: Office of Biological Services.

Day, J.W., C.A.S. Hall, W. Micheal Kemp, and A. Yáñez-Arancibia. 1989. Estuarine ecology, 50. New York: Wiley.

Diefenderfer, H.L., R.M. Thom, G.E. Johnson, J.R. Skalski, K.A. Vogt, B.D. Ebberts, G.C. Roegner, and E.M. Dawley. 2011. A levels-ofevidence approach for assessing cumulative ecosystem response to estuary and river restoration programs. Ecological Restoration 29: $111-132$

Diefenderfer, H.L. G.E. Johnson, R.M. Thom, K.E. Buenau, L.A. Weitkamp, C.M. Woodley, A.B. Borde, and R.K. Kropp. 2016. Evidence-based evaluation of the cumulative effects of ecosystem restoration. Ecosphere 7(3): e01242. doi:10.1002/ecs2.1242.

Ewing, K. 1986. Plant growth and productivity along complex gradients in a Pacific Northwest brackish intertidal marsh. Estuaries 9: 49-62.

FGDC (Federal Geographic Data Committee). 2012. Coastal and marine ecological classification standard. FGDC-STD-018-2012. Marine and Coastal Spatial Data Subcommittee, June, 2012. Available URL: http://www.fgdc.gov/standards/projects/FGDC-standardsprojects/cmecs-folder/CMECS_Version_06-2012_FINAL.pdf/ view.

FGDC (Federal Geographic Data Committee). 2013. Classification of wetlands and deepwater habitats of the United States. FGDCSTD-004-2013, 2nd edition. Wetlands Subcommittee, August 2013. Available URL: http://www.fgdc.gov/standards/projects/ FGDC-standards-projects/wetlands/nvcs-2013.

Foreman, M.G.G., W.R. Crawford, and R.F. Marsden. 1995. De-tiding: Theory and practice. In Coastal and estuarine studies, vol. 47, ed. D.R. Lynch and A.M. Davies, 203-239.

Fox, D.S., S. Bell, W. Nehlsen, and J. Damron. 1984. The Columbia River Estuary: atlas of physical and biological characteristics. Astoria: Columbia River Estuary Data Development Program.

Gallo, Marcos, and Susana Vinzon. 2005. Generation of overtides and compound tides in Amazon estuary. Ocean Dynamics 55: 5-6.

Georgas, N., B. Wen, and Y. Zhao. 2013. Final report calculation of vertical tidal datums for the tidal Hudson River north of Yonkers, New York. Hoboken: Stevens Institute of Technology. 25 pp. 
Geyer, W.R., J.T. Morris, F.G. Prahl, and D.A. Jay. 2000. Interaction between physical processes and ecosystem structure: a comparative approach. In Estuarine science: a synthetic approach to research and practice, ed. J.E. Hobbie, 177-206. Washington, D.C.: Island Press.

Giese, B.S., and D.A. Jay. 1989. Modeling tidal energetics of the Columbia River Estuary. Estuarine, Coastal and Shelf Science 29: 549-571.

Godin, G. 1999. The propagation of tides up rivers with special considerations on the Upper Saint Lawrence River. Estuarine, Coastal and Shelf Science 48: 307-324.

Gowing, D.J., and G. Spoor. 1998. The effects of water table depth on the distribution of plant species on lowland wet grasslands. In United Kingdom floodplains, ed. R. Bailey, P. Jose, and B. Sherwood, 185196. Otley: Westbury.

Guo, L., M. van der Wegen, D. A. Jay, P. Matte, Z. B. Wang, D. Roelvink, and Q. He. 2015. River-tide dynamics: Exploration of nonstationary and nonlinear tidal behavior in the Yangtze River estuary. $J$. Geophys. Res. Oceans 120. doi:10.1002/2014JC010491.

Hamlet, A.F., M.M. Elsner, G.S. Mauger, S.-Y. Lee, I. Tohver, and R.A. Norheim. 2013. An overview of the Columbia Basin Climate Change Scenarios Project: approach, methods, and summary of key results. Atmosphere-Ocean 51(4): 392-415. doi:10.1080/ 07055900.2013 .819555 .

Hidayat, H., A.J.F. Hoitink, M.G. Sassi, and P.J.J.F. Torfs. 2014. Prediction of discharge in a tidal river using artificial neural networks. Journal of Hydrologic Engineering 19(8): 04014006.

Horner-Devine, A.R., D.A. Jay, P.M. Orton, and E.Y. Spahn. 2009. A conceptual model of the strongly tidal Columbia River plume. Journal of Marine System 78: 460-475. doi:10.1016/j.jmarsys. 2008.11.025.

Huber, P. J., 1996. Robust statistical procedures, 2nd Ed. No. 68 in CBMS-NSF Regional Conference Series in Applied Mathematics Society of Industrial and Applied Mathematics.

Hudon, C. 1997. Impact of water level fluctuations on St. Lawrence River aquatic vegetation. Canadian Journal of Fisheries and Aquatic Sciences 54: 2853-2865.

Jay, D.A. 1991. Green's law revisited: tidal long wave propagation in channels with strong topography. Journal of Geophysical Research 96: 20,585-20,598.

Jay, D.A., and E.P. Flinchem. 1997. Interaction of fluctuating river flow with a barotropic tide: a test of wavelet tidal analysis methods. Journal of Geophysical Research 102: 5705-5720.

Jay, D.A., and P. Naik. 2011. Distinguishing human and climate influences on hydrological disturbance processes in the Columbia River USA. Hydrological Sciences Journal 56: 1186-1209.

Jay, D.A., and C.A. Simenstad. 1996. Downstream effects of water withdrawal in a small, high-gradient basin: erosion and deposition on the Skokomish River Delta. Estuaries 19: 501-517.

Jay, D.A., and J.D. Smith. 1990. Circulation, density distribution and neap-spring transitions in the Columbia River Estuary. Progress in Oceanography 25: 81-112.

Jay, D.A., B.S. Giese, and C.R. Sherwood. 1990. Energetics and sedimentary processes in the Columbia River Estuary. Progress in Oceanography 25: 157-174.

Jay, D.A., K. Leffler, and S. Degens. 2011. Long-term evolution of Columbia River tides. ASCE Journal of Waterway, Port, Coastal, and Ocean Engineering 137: 182-191. doi:10.1061/(ASCE)WW. 1943-5460.0000082.

Jay, D.A., K. Leffler, H.L. Diefenderfer, and A.B. Borde. 2014. Tidalfluvial and estuarine processes in the lower Columbia River, I. Along-channel water level variations, Pacific Ocean to Bonneville Dam. Estuaries and Coasts 38: 415-433.

Junk, W.J. 1999. The flood pulse concept of large rivers: learning from the tropics. Archiv für Hydrobiologie, Supplement 115: 261-280.
Kingsford, R.T. 2000. Ecological impacts of dams, water diversions and river management on floodplain wetlands in Australia. Austral Ecology 25: 109-127.

Kuchler, A.W. 1964. Manual to accompany the map potential natural vegetation of the conterminous United States. New York: American Geographical Society, Special Publication No. 36.

Kukulka, T., and D.A. Jay. 2003a. Impacts of Columbia River discharge on salmonid habitat I. a non-stationary fluvial tide model. Journal of Geophysical Research 108: 3293. doi:10.1029/2002JC001382.

Kukulka, T., and D.A. Jay. 2003b. Impacts of Columbia River discharge on salmonid habitat II. Changes in shallow-water habitat. Journal of Geophysical Research 108: 3294. doi:10.1029/2003JC001829.

Kunze, L.M. 1994. Preliminary classification of native, low elevation, freshwater wetland vegetation in Western Washington. Olympia: Washington State Department of Natural Resources.

Leffler, K., and D.A. Jay. 2009. Enhancing tidal harmonic analysis: Robust (hybrid L1/L2) solutions. Continental Shelf Research 29: $78-88$.

Leyer, I. 2005. Predicting plant species' responses to river regulation: the role of water level fluctuations. Journal of Applied Ecology 42: 239-250.

Longuet-Higgins, M.S. 1969. On the transport of mass by time-varying ocean currents. Deep Sea Research and Oceanographic Abstracts 16: 431-447.

Matte, P., Y. Secretan, and J. Morin. 2014. Temporal and spatial variability of tidal-fluvial dynamics in the St. Lawrence fluvial estuary: An application of nonstationary tidal harmonic analysis. Journal of Geophysical Research, Oceans 119: 5724-5744. doi:10.1002/ 2014JC009791.

Moffett, K.B., D.A. Robinson, and S.M. Gorelick. 2010. Relationship of salt marsh vegetation zonation to spatial patterns in soil moisture, salinity, and topography. Ecosystems 13: 1287-1302.

Naik, P., and D.A. Jay. 2011. Distinguishing human and climate influences on the Columbia River: changes in mean flow and sediment transport. Journal of Hydrology 404(3-4): 259-277.

National Marine Fisheries Service (NMFS). 2008. Biological Opinion Consultation on Remand for Operation of the Federal Columbia River Power System, 11 Bureau of Reclamation Projects in the Columbia Basin and ESA Section 10(a)(1)(A) Permit for Juvenile Fish Transportation Program. NMFS (National Oceanic and Atmospheric Administration Fisheries) - Northwest Region, Seattle, Washington.

National Research Council (NRC). 2012. Sea-level rise for the coasts of California, Oregon, and Washington: past, present, and future. Washington, D.C.: National Academies Press.

Natural Resource Conservation Service (NRCS). 2002. Wetland determination (WETS) table for Clark County, Washington. Natural Resource Conservation Service, U.S. Department of Agriculture, Washington, D.C. Available at http://www.wcc.nrcs.usda.gov/ ftpref/support/climate/wetlands/wa/53011.txt (May 2012).

O'Connor, J.E. 2004. The evolving landscape of the Columbia River Gorge-Lewis and Clark and cataclysms on the Columbia. Oregon Historical Quarterly 105: 390-421.

Odum, W.E. 1988. Comparative ecology of tidal freshwater and salt marshes. Annual Review of Ecology and Systematics 19: 147-176.

Opperman, J.J., G.E. Galloway, J. Fargione, J.F. Mount, B.D. Richter, and S. Secchi. 2009. Sustainable floodplains through large-scale reconnection to rivers. Science 326: 1487-1488.

Pawlowicz, R., R. Beardsley, and S. Lentz. 2002. Classical tidal harmonic analysis with errors in matlab using t-tide. Computers and Geosciences 28: 929-937.

Pennings, S.C., M.B. Grant, and M.D. Bertness. 2005. Plant zonation in low-latitude salt marshes: disentangling the roles of flooding, salinity and competition. Journal of Ecology 93: 159-167.

Peterson, M. 2003. A conceptual view of environment-habitat-production linkages in tidal river estuaries. Reviews in Fisheries Science 11: 291-313. 
Picket, S.T.A., and P.S. White. 1985. The ecology of natural disturbance and patch dynamics. San Diego: Academic.

Poff, N.L., J.D. Allan, M.B. Bain, J.R. Karr, K.L. Prestergaard, B.D. Richter, R.E. Sparks, and J.C. Stromberg. 1997. The natural flow regime: a paradigm for river conservation and restoration. BioScience 47: 769-784.

Qian, Y., W.I. Gustasfson, L.R. Leung, and S.J. Ghan. 2009. Effects of soot-induced albedo change on snowpack and hydrological cycle in Western United States based on weather research forecasting chemistry and regional climate simulations. Journal of Geophysical Research 114, D03108. doi:10.1029/2008JD011039.

Rieman, B., J. Dunham, and J. Clayton. 2006. Emerging concepts for management of river ecosystems and challenges to applied integration of physical and biological sciences in the Pacific Northwest, USA. International Journal of River Basin Management 4: 85-97.

Roegner, G.C., H.L. Diefenderfer, A.B. Borde, R.M. Thom, E.M. Dawley, A.H. Whiting, S.A. Zimmerman, and G.E. Johnson. 2009. Protocols for monitoring habitat restoration projects in the lower Columbia River and estuary. U.S. Dept. Commer., NOAA Tech. Memo. NMFS-NWFSC-97, 63 pp.

Sagar, J.P., A. B. Borde, L.L. Johnson, T. Peterson, J. Needoba, C. A. Corbett, K. H. Macneale, M. Schwartz, A. Silva, V.I. Cullinan, S. A. Zimmerman, R. M. Thom, P.M. Chittaro, O. P. Olson, S. Y. Sol, D. J. Teel, and G. M. Ylitalo. 2014. Juvenile salmon ecology in tidal freshwater wetlands of the lower Columbia river and estuary: Synthesis of the ecosystem monitoring program, trends (20052013) and food web dynamics (2011-2013). Prepared by the Lower Columbia Estuary Partnership for the Bonneville Power Administration. Available from the Lower Columbia Estuary Partnership, Portland, OR.
Salathé Jr., E.P., A.F. Hamlet, C.F. Mass, S.-Y. Lee, M. Stumbaugh, and R. Steed. 2014. Estimates of twenty-first-century flood risk in the Pacific Northwest based on regional climate model simulations. Journal Hydrometeor 15(5): 1881-1899. doi:10.1175/JHM-D-13-0137.1.

Sassi, M.G., A.J.F. Hoitink, B. de Brye, B. Vermeulen, and E.C. Deleersnijder. 2011. Tidal impact on the division of river discharge over distributary channels in the Mahakam Delta. Ocean Dynamics 61: 2211-2228.

Sharpe, P.J., and A.H. Baldwin. 2009. Patterns of wetland plant species richness across estuarine gradients of Chesapeake Bay. Wetlands 29(1): 225-235.

Sharpe, P.J., and A.H. Baldwin. 2013. Wetland plant species richness across estuarine gradients: the role of environmental factors and the mid-domain effect. Aquatic Botany 107: 23-32.

Sherwood, C.R., D.A. Jay, R.B. Harvey, P. Hamilton, and C.A. Simenstad. 1990. Historical changes in the Columbia River estuary. Progress in Oceanography 25: 299-352.

Simenstad, C.A., J.L. Burke, J.E. O’Connor, C. Cannon, D.W. Heatwole, M.F. Ramirez, I.R. Waite, T.D. Counihan, and K.L. Jones. 2011. Columbia river estuary ecosystem classification - concept and application. U.S. Geological Survey Open-File Report 2011-1228, 60 p.

Templeton, W., and D.A. Jay. 2013. Lower Columbia River sand supply and removal: estimates of two sand budget components. ASCE Journal of Waterway, Port, Coastal and Ocean Engineering.. doi: 10.1061/(ASCE)WW.1943-5460.0000188.

Thomas, D.W. 1984. The vascular flora of the Columbia River Estuary. Wasmann Journal of Biology 42(1-2): 92-106.

U.S. Geological Survey (USGS). 2012. Columbia River Estuary Ecosystem Classification, Geomorphic Catena. Available at: http://water.usgs.gov/ GIS/metadata/usgswrd/XML/creec_geomorphic_catena.xml. 